\title{
Los Assamiidae (Opiliones: Assamiidae) de Río Muni (Guinea Ecuatorial), con la descripción de ocho nuevas especies
}

\author{
Rakel Santos ${ }^{1} \&$ Carlos E. Prieto ${ }^{2}$ \\ 1. Departamento de Territorio y Biodiversidad, IKT, Granja Modelo, 01192-Arkaute (Alava, España); rsantos@ikt.es \\ 2. Departamento de Zoología, Universidad del País Vasco/EHU, Apdo.644, 48080-Bilbao (España); \\ carlos.prieto@ehu.es
}

Recibido 25-II-2009. Corregido 08-VIII-2009. Aceptado 10-IX-2009.

\begin{abstract}
The Assamiidae (Opiliones: Assamiidae) from Río Muni (Equatorial Guinea), with the description of eight new species. The Opiliones from Equatorial Guinea's Continental Region (formerly Río Muni) had not been studied previously. A collection made in 1996 produced 22 species, ten of which belong to the Assamiidae and are studied herein: Chilon robustus and Mbinia xenophora gen. nov., sp. nov. (Erecinae); Podauchenius longipes and Rhabdopygus funilignorum sp. nov. (Hypoxestinae); Ayenea trimaculata gen. nov., sp. nov., Montalenia forficula gen. nov., sp. nov. and Niefanga spinosa gen. nov., sp. nov. (Polycoryphinae); Binderia longipes sp. nov., Seuthes inermis sp. nov. and Seuthessus coriscanus sp. nov. (Selencinae). We consider Ayenea, Montalenia and Niefanga an informal suprageneric group characterized by two orifices on the dorsal side of the penis and a thick genital operculum. Identification keys to species of these taxa are provided, together with color photographs of both sexes (except the female of Binderia longipes). Eight of the ten assamiid species have been recorded from the Monte Alén National Park; only two selencine species (apparently coastal) are absent. Rev. Biol. Trop. 58 (1): 203-243. Epub 2010 March 01.
\end{abstract}

Key words: Opiliones, Assamiidae, Gulf of Guinea, Equatorial Guinea, Río Muni, Monte Alén National Park.

La fauna afrotropical del orden Opiliones está muy pobremente conocida. Starȩga (1984, 1992) censa las especies africanas de este orden, el cuál con la incorporación de los escasos datos publicados posteriormente (Giribet \& Prieto 2003, Kury 2004, 2006, Bauer \& Prieto 2009, Prieto en prensa) alcanza las 715 especies, pero con una distribución muy desigual: únicamente la República de Suráfrica, con 190 especies, presenta un nivel de conocimiento similar al de varios países de Europa. La República Democrática del Congo con 142 y Tanzania con 99 especies son los dos siguientes países mejor conocidos, pero hay diez países de los que no se conoce ni un dato. Los países del Golfo de Guinea presentan un conocimiento muy precario, especialmente Nigeria con tres especies y Congo con seis; Camerún con 50 especies es el mejor conocido, mientras que Guinea Ecuatorial alberga 23 especies.

Guinea Ecuatorial es un pequeño estado situado en el fondo del golfo de Guinea y comprende las islas de Bioko (antes Fernando Póo) y Pagalu (o Annobón) y la Región Continental, Río Muni o Mbini, cada una de ellas con muy diferente grado de conocimiento opilionológico. La isla de Fernando Póo era la colonia española en el golfo de Guinea con mayor actividad gracias a la gran fertilidad de los suelos volcánicos y la existencia de elevados valles y calderas, con clima menos severo, que permitían variados cultivos y asentamientos coloniales, y debido a la presencia habitual de europeos, la actividad recolectora fue mayor. Los primeros opiliones de Fernando Póo, recogidos por Leonardo Fea en 1902 durante su 
expedición al golfo de Guinea, fueron descritos por H. J. Hansen y Carl F. Roewer. Hansen (1921) estudia los Cyphophthalmi y Eupnoi y describe cuatro especies, Parogovia sironoides, Ogovea nasuta, Dacnopilio insularis y Megistobunus longipes (Cuadro 1). Los Laniatores fueron estudiados por Roewer (1927), quien añadió cuatro nuevas especies (Musola longipes, Selenca minuscula, Selenca filipes, Pyramidops albimana) y mencionó otras siete más. Las siguientes aportaciones también se deben a Roewer (1942, 1949): en la primera describe Biantomma nigrospinosum y en la segunda Conomma oedipus y Pyramidops biseriata, todas endémicas de la isla. La última aportación (Prieto 1999) estudia una pequeña colección de opiliones guineanos del Museo Nacional de Ciencias Naturales (MNCN, Madrid), recogidos en 1933 por los entomólogos Federico Bonet y Juan Gil durante una expedición del propio Museo, e identifica ocho especies de Bioko, que aumentan a 23 el listado faunístico de la isla: dos se citan por primera vez para la isla (una como subespecie propia) y cuatro especies se anunciaban como nuevas, pero dos de ellas resultaron ser el macho y la hembra de Microconomma armatipes Roewer 1949, una vez revisado el holotipo (datos no publicados).

\section{CUADRO 1}

Especies citadas para la isla de Bioko

TABLE 1

Recorded species from Bioko Island

\begin{tabular}{|c|c|c|c|c|}
\hline \multirow{2}{*}{\multicolumn{2}{|c|}{ Familia sf }} & Especie & Rango geográfico & Localidades en BIOKO \\
\hline & Neogoveidae & Parogovia sironoides Hansen & Bioko & Basilé, Punta Frailes \\
\hline \multicolumn{2}{|l|}{ Ogoveidae } & Ogovea nasuta (Hansen) & Bioko & Musola \\
\hline \multirow{2}{*}{\multicolumn{2}{|c|}{ Phalangiidae }} & Dacnopilio insularis Hansen & Bioko & Moka, Baney \\
\hline & & Megistobunus longipes Hansen & Bioko & Basilé, ¿loc? \\
\hline \multirow[t]{9}{*}{ Assamiidae } & $\mathrm{E}$ & Cerea feai Roewer & Gabón + Bioko & Basilé, Musola, Basilé \\
\hline & $\mathrm{E}$ & Chilon horridus (Roewer) & Camerún + Bioko & Basilé \\
\hline & $\mathrm{E}$ & Chilon robustus Sørensen & C. Marfil/Congo: $3000 \mathrm{~km}$ & 3 loc + Sta. Isabel, Biapa \\
\hline & $\mathrm{H}$ & Musola longipes Roewer & Bioko & Musola \\
\hline & $\mathrm{P}$ & Bueana (quadridentata) & Bioko & Rebola, Baney \\
\hline & $\mathrm{S}$ & Eupodauchenius luteocruciatus (Loman) & C.Marfil/Gabón: 2 500km & Basilé \\
\hline & $\mathrm{S}$ & Euselenca feai Roewer & Gabón + Bioko & Basilé \\
\hline & $\mathrm{S}$ & Selencasta minuscula (Roewer) & Bioko & Fernando Póo (loc?) \\
\hline & $\mathrm{S}$ & Selencula filipes (Roewer) & Bioko & Basilé \\
\hline \multirow{7}{*}{\multicolumn{2}{|c|}{ Gr. Pyramidops }} & Conomma fortis Loman & G.Bissau/Camerún: 3 000km & Basilé, B.Oeste, Musola \\
\hline & & Conomma minima Roewer & G.Bissau/Camerún: 3 000km & Basilé, Punta Frailes \\
\hline & & Conomma oedipus Roewer & Bioko & Fernando Póo (loc?) \\
\hline & & Conomma (sorianoi) & Bioko & Botonos, Malabo \\
\hline & & Pyramidops albimana Roewer & Bioko & Basilé \\
\hline & & Pyramidops biseriata Roewer & Bioko & Fernando Póo (loc?) \\
\hline & & Pyramidops raptator (Sørensen) & Camerún + Bioko & Basilé \\
\hline \multirow{2}{*}{\multicolumn{2}{|c|}{ Biantidae }} & Biantomma nigrospinosum Roewer & Bioko & Pico S.Isabel \\
\hline & & Lacurbs (fernandopoensis) & Bioko & Rebola \\
\hline \multicolumn{2}{|l|}{ Samoidae } & Microconomma armatipes Roewer & Camerún + Bioko & Malabo \\
\hline
\end{tabular}

Las subfamilias de Assamiidae (Erecinae, Hypoxestinae, Polycoryphinae, Selencinae) se indican con su inicial. Los nuevos taxones citados por Prieto (1999), aún por publicar, van entre paréntesis y sus nuevos registros en negrita.

Assamiidae subfamilies (Erecinae, Hypoxestinae, Polycoryphinae, Selencinae) are indicated by their initial capitals. New taxa cited by Prieto (1999), still unpublished, go between parentheses and his new records in bold cases. 
De la pequeña isla de Annobón (o Pagalu) sólo se conocen tres especies, Conomma fortis Loman 1902, Conomma minima Roewer 1912 y Conomma principea Roewer 1949, señaladas por Roewer (1927, 1949). Ninguna es endémica de la isla, y todas han sido citadas de las islas de Bioko o Príncipe; probablemente sean introducciones recientes.

Por último, el conocimiento opilionológico de la Región Continental o Río Muni, objeto del presente trabajo, es nulo; no hay ni un único dato bibliográfico a pesar de que se han realizado varias recolecciones aracnológicas en la zona:

- Amado Ossorio (1886) publicó los apuntes de su viaje a la región del Muni junto a una enumeración y estudio de las colecciones recogidas en la que Ignacio Bolívar identificaba los "Articulados", mencionando numerosas especies de insectos y sólo dos arácnidos (Mygale occidentalis Lucas 1858, Araneae: Theraphosidae, y Lychas guineensis Lucas 1858, Scorpiones: Buthidae).

- Manuel Iradier (1887), en las memorias de sus exploraciones y andanzas en la cuenca del Muni, y en un capítulo dedicado a las producciones del país, señaló que la colección de "articulados", "bastante numerosa, se perdió por completo en el país y sólo llegaron a España (...) 5 arañas, 5 escorpiones, 2 palaemon y 1 Ascaris cuya clasificación encargada al reputado entomólogo D. Ignacio Bolivar no estaba terminada en el momento de dar este capitulo a la imprenta". Una parte de este material parecen ser dos muestras de Isometrus maculatus (De Geer 1778), Scorpiones: Buthidae, procedentes de Fernando Póo y Elobey conservadas en el MNCN. En el mismo frasco, hay otra muestra de la misma especie con la etiqueta "Río Muni (Guinea Española) Reg. Ossorio" aunque Ossorio (1886) no mencionó la recolección de escorpiones.

- El entomólogo Manuel Martínez de la Escalera participó en dos expediciones zoológicas a las posesiones españolas del
Golfo de Guinea. La primera, de julio a octubre de 1901, como participante de una comisión hispano-francesa para el reconocimiento de límites y enviado por el MNCN; según Hidalgo (1910), quien estudia los moluscos, sólo se recogió material biológico en los alrededores del Cabo San Juan. No hay duda de que las recolecciones de arácnidos fueron muy abundantes puesto que en el MNCN se conservan numerosos araneidos de Cabo San Juan identificados y publicados por Simon (1903). No se ha encontrado allí ningún opilión de los que, con total seguridad, debió recoger Martínez de la Escalera. Sin embargo, se ha podido determinar que dichos opiliones se encontraban en el MNHN (París), donde una pequeña colección de once especies estaba erróneamente considerada como procedente del Camerún.

- Según Bofill \& Aguilar-Amat (1924), “El Museo de Ciencias Naturales de Barcelona comisionó, en 1919, a D. Manuel Martínez de la Escalera, para que procediese a la recolección de ejemplares de Mamiferos, Aves, Reptiles e Insectos en las posesiones españolas del Golfo de Guinea". Las recolecciones no se ciñeron estrictamente al encargo pues los autores citados identificaron doce especies de moluscos terrestres; muy probablemente se recogieron también arácnidos y deberían estar en el Museo de Zoología de Barcelona.

- En 1933, el MNCN envía una expedición formada por Federico Bonet y Juan Gil Collado a la isla de Bioko (con incursión a la región continental). Este material permaneció olvidado, sin catalogar ni identificar, en los sótanos del MNCN donde fue encontrado por C. Prieto. La identificación del material de la isla de Bioko (ver arriba) fue avanzada por Prieto (1999) pero no fueron incluidos los opiliones procedentes de Río Benito, en la entonces Guinea española: sólo son tres ejemplares, pero de tres especies nuevas (sólo una de la familia Assamiidae). 
Hasta hoy, Río Muni ha sido terra incognita para el orden Opiliones. En agosto de 1996, una expedición ligera a la región continental destinada a la recolección de briófitos (Patxi Heras, Museo de Ciencias Naturales de Alava) y gasterópodos terrestres (C. Prieto) permitió la captura de diversos Opiliones durante las recogidas malacológicas. La determinación preliminar resultó mayoritariamente infructuosa debido a que muy pocos ejemplares podían ser reconocidos como especies ya descritas, lo que se podía aplicar al emplazamiento genérico. El estudio definitivo fue abordado por R. Santos como tesis de licenciatura, lo cual permitió reconocer la presencia de 22 especies, repartidas en tres familias: Biantidae con cinco especies, el grupo Pyramidops con siete especies, y Assamiidae con diez especies (ocho de ellas nuevas para la ciencia) y objeto de este trabajo.

\section{MATERIAL Y MÉTODOS}

Abreviaturas. Los especímenes estudiados se alojan en las siguientes instituciones:

ZUPV: Dpto. de Zoología, Universidad del País Vasco (Bilbao, España) (col. Prieto)

MNCN: Museo Nacional de Ciencias Naturales (Madrid, España)

MRAC: Musée Royal de l'Afrique Centrale (Tervuren, Bélgica)

La mayor parte del material estudiado procede de las recolecciones efectuadas por C. Prieto en agosto de 1996 (Fig. 1 y Cuadro 2). Además, se han incorporado tres muestras más: una de otra colección efectuada por los autores en verano de 2001 (Corisco: Punta Koto), en proceso de estudio, para completar la descripción de una de las nuevas especies; otra corresponde a un material prestado por el $\mathrm{MNCN}$, recolectado en 1933 por Federico Bonet \& Juan

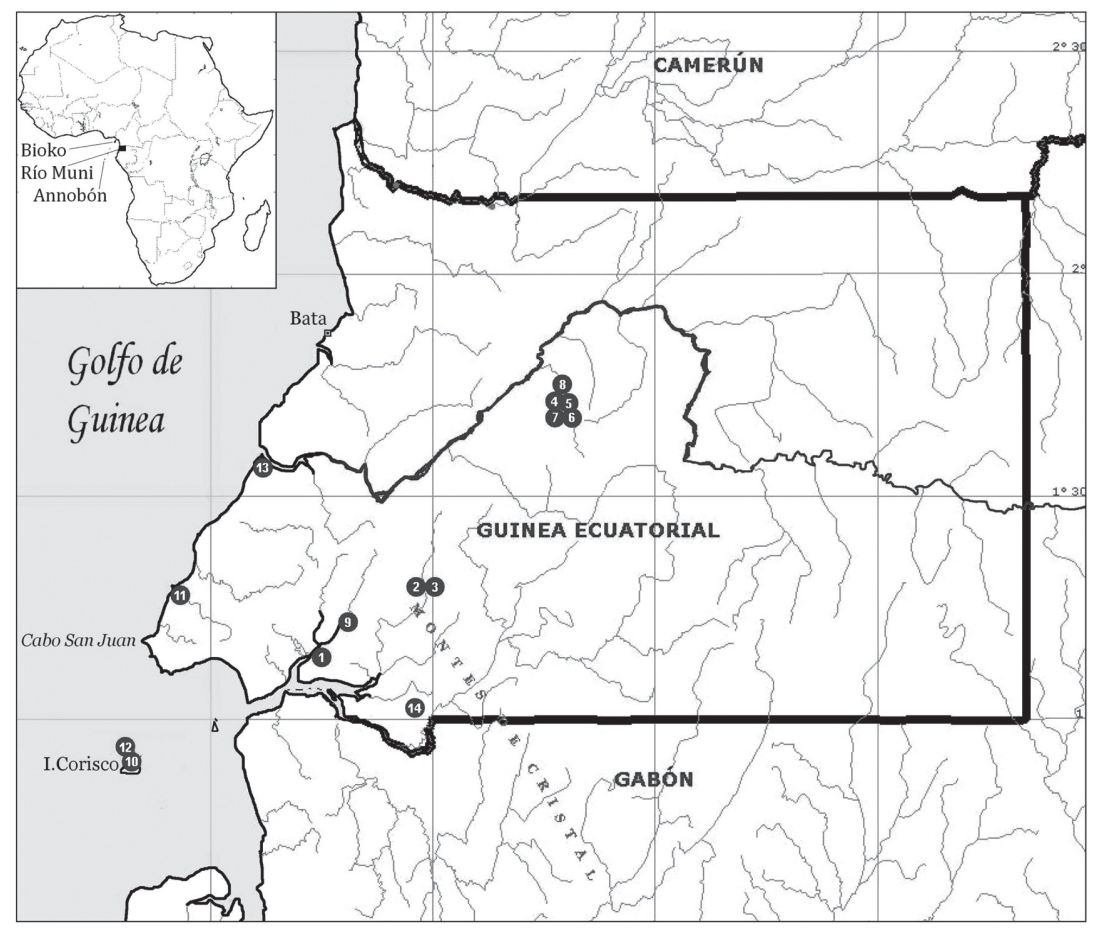

Fig. 1. Mapa de Río Muni, la Región Continental de Guinea Ecuatorial, con las localidades de procedencia del material investigado.

Fig. 1. Map of Río Muni, the Continental Region of Equatorial Guinea, with sampling localities. 
CUADRO 2

Localidades de Río Muni donde se han obtenido opiliones

TABLE 2

Localities from Rio Muni where harvestmen were gathered

\begin{tabular}{|c|c|c|c|c|c|c|c|}
\hline $\mathrm{N}^{\mathrm{o}}$ & Localidad & UTM & Fecha & Hábitat & Assamiidae & Biantidae & Gr.Pyram. \\
\hline 1 & Río Muni: junto estuario & $32 \mathrm{NNG} 8020$ & 21.08 .1996 & bosque $2^{\circ}$ & & M1 & \\
\hline 2 & Río Motora (Mitong): puente, $1 \mathrm{~km} \mathrm{E}$ & 32NPG0839 & 23.08 .1996 & bosque $1^{\circ}$ & ACPRS & $\mathrm{Ba} \mathrm{M} 1,2$ & $\mathrm{~Pb} \mathrm{Pt}$ \\
\hline 3 & Río Motora (Mitong): puente, $3 \mathrm{~km} \mathrm{E}$ & 32NPG1039 & 04.09 .1996 & bosque $1^{\circ}$ & ARS & & \\
\hline 4 & PNMA*: Monte Alén: vertiente NW & 32NPG4484 & 29.08 .1996 & bosque $1^{\circ}$ & ACEMNP & & \\
\hline 5 & PNMA: Monte Alén: cima & 32NPG4584 & 29.08 .1996 & bosque $1^{\circ}$ & MPR & & $\operatorname{Pr}$ \\
\hline 6 & PNMA: hasta Itinerario Pedagógico & $32 \mathrm{NPG} 4583$ & 27.08 .1996 & bosque $1^{\circ}$ & ACEMN & & $\mathrm{Pa}$ \\
\hline 7 & PNMA: camino del Mirador & $32 \mathrm{NPG} 4483$ & 27.08.1996 & bosque $1^{\circ}$ & M & & \\
\hline 8 & PNMA: Ayene: cabecera río & $32 \mathrm{NPG} 4386$ & 28.08 .1996 & bosque $1^{\circ}$ & $\mathrm{ABCNR}$ & & \\
\hline 9 & Río Congüe: bosque de elondo & 32NNG8935 & 05.09 .1996 & bosque $1^{\circ}$ & CRS & M1 & $\mathrm{Pb} \mathrm{Pt}$ P1 \\
\hline 10 & Isla de Corisco: Lago Aukati & 32NNG3500 & 01.09 .1996 & bosque $2^{\circ}$ & $\mathrm{U}$ & $\mathrm{Cp}$ & Pc \\
\hline 11 & Etembue: ruinas fábrica & 32NNG4741 & 03.09 .1996 & maleza & & Ls M2 & \\
\hline 12 & Isla de Corisco: Punta Koto & $32 \mathrm{NNG} 3403$ & 12.07.2001 & bosque $2^{\circ}$ & $\mathrm{U}$ & & \\
\hline 13 & Río Benito (=Mbini?) [MNCN] & 32NNG6-7- & xx.03.1933 & & $\mathrm{S}$ & & $\mathrm{Pb} \mathrm{Ug}$ \\
\hline 14 & Btw.Mbane and Abenelang [MRAC] & 32NPG1111 & 22.07.1989 & & S & & \\
\hline
\end{tabular}

Los taxones encontrados para cada familia se indican con abreviaturas: Assamiidae (A: Ayenea, B: Binderia, C: Chilon, E: Mbinia, M: Montalenia, N: Niefanga, P: Podauchenius, R: Rhabdopygus, S: Seuthes, U: Seuthessus), Biantidae (Ba: gen. \& sp. nov., Cp: Clinobiantes sp., Ls: Lacurbs sp., M1, M2: Metabiantes spp.nov.) y grupo Pyramidops (Pa Pb Pc Pr Pt P1: Pyramidops spp.nov., Ug: gen.\&sp.n.). PNMA*: Parque Nacional de Monte Alén.

Recorded taxa for each family are indicated by acronyms: Assamiidae (A: Ayenea, B: Binderia, C: Chilon, E: Mbinia, M: Montalenia, N: Niefanga, P: Podauchenius, R: Rhabdopygus, S: Seuthes, U: Seuthessus), Biantidae (Ba: gen. \& sp. nov., Cp: Clinobiantes sp., Ls: Lacurbs sp., M1, M2: Metabiantes spp.nov.) and Pyramidops group (Pa Pb Pc Pr Pt P1: Pyramidops spp.nov., Ug: gen.\&sp.n.). PNMA*: Monte Alén National Park.

Gil en "Río Benito", actualmente Mbini; la tercera procede del MRAC y fue recogida por M. Alderweireldt en 1989.

La nomenclatura utilizada sigue los esquemas tradicionales de autores como Roewer, Lawrence y Kauri. La longitud relativa de los cinco procesos frontales del carapacho (izquierdos, central y derechos) se expresa mediante una serie de cinco cifras. Los números romanos se refieren indistintamente a patas, áreas del escudo o terguitos libres. Las medidas de todos los especímenes (longitud y ancho del cuerpo, longitud de las patas) se han realizado mediante cámara clara y se presentan en el Cuadro 3. Las medidas se expresan en milímetros.

\section{TAXONOMÍA}

\section{Familia Assamiidae Sørensen 1884}

La familia Assamiidae es fácilmente diagnosticable por la presencia de cinco procesos del borde frontal del escudo prosómico (central, dos laterales internos y dos laterales externos o marginales), pedipalpos no muy largos, con tibia y tarso dorsoventralmente aplanados y cruzados uno sobre otro (Roewer 1935), y tarsos de las patas III y IV sin proceso tarsal (pseudoniquio) ni escópula. El pene también es fácilmente reconocible por presentar un tronco distalmente ensanchado y aplanado 
CUADRO 3

Medidas del cuerpo y de las patas de los especímenes descritos

TABLE 3

Measurements of body and legs of studied specimens

\begin{tabular}{|c|c|c|c|c|c|c|c|}
\hline & & \multicolumn{2}{|c|}{ Cuerpo } & \multicolumn{4}{|c|}{ Patas } \\
\hline & & Longitud & Anchura & I & II & III & IV \\
\hline \multirow[t]{2}{*}{ Chilon robustus } & Machos (1) & 3.81 & 2.87 & 11 & 23.5 & 14 & 19.5 \\
\hline & Hembras (6) & $3.62-4.5$ & $2.62-2.93$ & $10-11$ & $21-23.5$ & $12.5-14$ & $17.5-19.5$ \\
\hline \multirow[t]{2}{*}{ Mbinia xenophora } & Holotipo $\sigma^{\pi}$ & 4. 4 & 2.8 & 13.5 & 29.5 & 15 & 21 \\
\hline & Paratipo $q$ & 5.92 & 3.58 & 11.5 & 26 & 14 & 19.5 \\
\hline \multirow[t]{2}{*}{ Podauchenius longipes } & Machos (2) & $3.65-3.8$ & $2.9-3.0$ & $30-31$ & $101-116$ & $35-37$ & $45-48$ \\
\hline & Hembras (2) & $3.9-3.95$ & $2.6-2.75$ & $19-21$ & $47-53$ & $24-26$ & -35 \\
\hline \multirow[t]{3}{*}{ Rhabdopygus funilignorum } & Holotipo & 6.18 & 3.81 & 12.5 & 24 & 16.5 & 22 \\
\hline & Machos (8) & $5.55-6.2$ & $3.45-3.8$ & $11.5-12.5$ & $22-24.5$ & $15.5-17$ & $21-23$ \\
\hline & Hembras (13) & $6.3-7.5$ & $3.55-4.35$ & $11.5-13.5$ & $22-25.5$ & $15.5-17.5$ & $21.5-24$ \\
\hline \multirow[t]{3}{*}{ Seuthessus coriscanus } & Holotipo & 3.85 & 2.4 & 10.4 & 18.2 & 13.5 & 19.1 \\
\hline & Machos (4) & $3.65-4.0$ & $2.3-2.4$ & $10-10.4$ & 17.1-18.2 & $13.2-13.5$ & $17.7-19.1$ \\
\hline & Hembras (3) & $3.7-4.6$ & $2.2-2.6$ & $9.7-10.3$ & $16.9-18.5$ & $12.7-13.6$ & 17.6-19 \\
\hline \multirow[t]{3}{*}{ Seuthes inermis } & Holotipo & 4.35 & 2.5 & 10.5 & 19 & 14 & 19 \\
\hline & Machos (3) & $3.75-4.35$ & $2.3-2.5$ & $10.3-10.6$ & $18.3-19$ & $13.3-14$ & $18.4-19.3$ \\
\hline & Hembras (4) & $3.7-4.5$ & $2.15-2.5$ & $10.6-11.8$ & $8.6-20.7$ & $13.8-15.5$ & $18-21.6$ \\
\hline Binderia longipes & Holotipo & 3.9 & 2.3 & 15.25 & 32 & 19.25 & 27.5 \\
\hline \multirow[t]{3}{*}{ Ayenea trimaculata } & Holotipo & 3.5 & 2.1 & 15.5 & 31 & 18 & 26 \\
\hline & Machos (7) & $3.1-3.5$ & $1.9-2.1$ & $14.5-16$ & $27-32.5$ & $17-19$ & $24-26.5$ \\
\hline & Hembras (7) & $4.5-5.5$ & $2.5-3.0$ & $14-15.5$ & $27-30.5$ & $16-18$ & $21.5-24.5$ \\
\hline \multirow[t]{2}{*}{ Niefanga spinosa } & Holotipo & 2.55 & 1.43 & 8.5 & 16.2 & 10.2 & 14 \\
\hline & Hembras (3) & $3.12-3.65$ & $1.87-2.15$ & 8.5 & $16-16.2$ & $10.2-10.5$ & $13.5-14$ \\
\hline \multirow[t]{3}{*}{ Montalenia forficula } & Holotipo & 2.37 & 1.53 & 8.5 & 16 & 10.5 & 14 \\
\hline & Machos (4) & $2.25-2.5$ & $1.34-1.53$ & $7.5-8.5$ & $15-16$ & $9.5-10.5$ & $12.5-14$ \\
\hline & Hembras (3) & $3.75-4.15$ & $1.87-1.93$ & 8-9 & $15-15.5$ & 10 & $13-14.5$ \\
\hline
\end{tabular}

(lámina ventral), a veces bilobulado y con una dotación variable de sedas y un glande cilíndrico subdistal que aloja una membrana evaginable espinosa o verrugosa con forma de embudo o "Stacheltrichter" (Martens 1986). Kury (en Pinto-da-Rocha et al. 2007, 173-176) no avala los caracteres diagnósticos señalados por Roewer (1935), pero sí su delimitación y composición puesto que ambos coinciden en la inclusión de los Trionyxellinae en la familia Assamiidae.

Inicialmente Roewer (1923) sólo consideró tres subfamilias, Trionyxellinae, Dampetrinae y Assamiinae, pero más tarde (Roewer 1935) pulverizó esta clasificación al reconocer
17 subfamilias basadas en la diferente combinación de seis caracteres; la estructura de su cuadro diagnóstico (Roewer 1935, Fig. 8a) ilustra claramente la artificiosidad de su clasificación. Así, la división de los asámidos provistos de largas espinas en el fémur del pedipalpo en tres subfamilias (Harsadiinae, Maruinae y Sidaminae) resultaba innecesaria, lo cual fue puesto de manifiesto por Staręga (1992) cuando pasa los dos únicos géneros de Harsadiinae a la sinonimia de Amhara Pavesi 1897 (Sidaminae). Otro ejemplo es la sinonimización de Tsadsea Roewer 1935 (Tsadseinae), y Acanthocoryphus Roewer 1953, Bindercola Roewer 1935, Villiersiella Roewer 1953 y 
Kobacoryphus Roewer 1961 (Polycoryphinae) con Chilon Sørensen 1896 (Erecinae) efectuada por Starȩga (1992).

Mello-Leitão (1949) transfirió los asámidos provistos de un proceso tarsal (o pseudoniquio) en los tarsos de las patas III y IV a una familia independiente, Trionyxellidae, opinión que es seguida por Shear (1982) y aceptada en este trabajo. Igualmente, Pinto-da-Rocha (en Pintoda-Rocha et al. 2007, 168-171) utiliza como requisito para llegar a Assamiidae la ausencia del proceso tarsal en la clave de familias de Laniatores, pero no menciona Trionyxellidae como un taxón independiente. Sin embargo, no hay ninguna clasificación alternativa a la de Roewer, la cual todavía es aceptada por Suzuki (1985) o Kauri (1985), quien incorpora la nueva subfamilia Irumuinae, caracterizada por la subdivisión del metatarso II. Una gran dificultad para la ordenación sistemática de esta enorme familia estriba en el generalizado desconocimiento de la morfología penial, hasta el punto de que sólo se había descrito la de una sola especie africana cuando Martens (1986) publicó la diagnosis penial de la familia. Este aspecto ha sido parcialmente remediado por Kauri (1985), aunque todavía no se ha descrito la morfología penial de ningún representante africano de la subfamilia Polycoryphinae.

La clasificación roeweriana no es aceptada por Kury (en Pinto-da-Rocha et al. 2007), quien considera que los Assamiidae comprenden, al menos, cinco grandes grupos: los Dampetrinae de Australia y Papúa-Nueva Guinea, los típicos Assamiinae de India/Nepal, los géneros con pseudoniquio conocidos como Trionyxellinae de Sri Lanka/India, los Erecinae de África Central y los pequeños y ciegos Irumuinae centroafricanos de vida endógea. No obstante, y aunque la división en subfamilias de Kauri (1985) es probablemente artificial, consideramos que, de momento, es la manera más adecuada para comparar los nuevos taxones propuestos con los ya conocidos.

\section{Clave de las subfamilias africanas de Assamiidae:}

1. Metatarso II dividido en varios artejos... Irumuinae

-. Metatarso II entero . . . . . . . . . . . . . . . . . 2
2. Distitarso I entero ............... Aburistinae

-. Distitarso I dividido en 2 artejos ............ 3

-. Distitarso I dividido en 3 artejos ........ Acacinae

3. Tarsos III y IV con uñas pectinadas .... Selencinae

Tarsos III y IV con uñas lisas . . . . . . . . . . . . . .4

4. Fémur del pedipalpo con largas espinas ventrales...

Sidaminae

Fémur del pedipalpo con cortos dientes ventrales . .5

5. Espiráculos visibles y desprotegidos . . . . . . . 6

-. Espiráculos cubiertos y protegidos por formaciones

quitinosas $\ldots \ldots \ldots \ldots \ldots \ldots \ldots \ldots \ldots$

6. Margen anterior del carapacho con una espina

frontal .................. Assamiinae

Margen anterior del carapacho desarmado, sin

espina frontal. .............. Hypoxestinae

7. Margen anterior del carapacho con una espina

frontal ............... Polycoryphinae

Margen anterior del carapacho desarmado, sin

espina frontal. . . . . . . . . . . . . . E Erecinae

Selencinae incluye Eupodaucheniinae y Sidaminae incluye Maruinae

\section{Subfamilia ERECINAE Roewer 1935}

Comprende 79 géneros ampliamente repartidos por las regiones Etiópica (58 géneros) y Oriental (19 géneros), e incluso presente con dos géneros, Cardwella Roewer 1935 y Wintonia Roewer 1923, en la región Australiana. La mayoría de los géneros son monotípicos y conocidos únicamente por la descripción original, pero destacan Ereca Sørensen 1910 con 24 especies, Metereca Roewer 1923 con 15 y Chilon con 9. Atendiendo al número de artejos del distitarso II, los erecinos africanos pueden dividirse en tres grupos: el grupo Ereca, característico de África oriental (con algunas especies llegando hasta Angola y el oeste de la R.D. Congo); el grupo Cerea Sørensen 1896, restringido a Camerún y Gabón, y finalmente un grupo heterogéneo de géneros con tres artejos, extendido por todo el Golfo de Guinea, desde Costa de Marfil hasta Angola.

En la región del Golfo de Guinea, incluyendo hasta la parte occidental de la R.D. del Congo, la subfamilia está representada por 21 géneros (Lawrence 1949, 1951, 1957, 1965, Roewer 1923, 1935, 1940, 1950, 1953, 1961); además de Chilon, Ereca y Metereca (con amplia distribución geográfica), los restantes se localizan en Costa de Marfil: Ivocoryphus Lawrence 1965 y Neocoryphus Lawrence 
1965; Camerún/Bioko: Bibundina Roewer 1935, Cerea, Cereatta Roewer 1935, Cereipes Roewer 1935, Cereodiscus Roewer 1935, Cereoides Roewer 1935, Fakoa Roewer 1923 y Mandaria Roewer 1935; W-R.D. Congo: Ereala Roewer 1950, Erecongoa Roewer 1950, Eregonda Roewer 1950 y Termitereca Roewer 1940; Angola: Angolyppa Lawrence 1957, Angopygoplus Lawrence 1951, Callereca Roewer 1940 (Callereca angolensis Lawrence 1949) y Lygippus Roewer 1940.

\section{Clave abreviada para los géneros del Golfo de Guinea:}

1. Distitarso II con 2 artejos ... Ereca y géneros afines

-. Distitarso II con 3 artejos ................

-. Distitarso II con 4 artejos ... Cerea y géneros afines

2. Tarso I con 3-4; tarsos III-IV con 4-5 artejos....... ... . . . . . . . . Mandaria, Lygippus, Angopygoplus

-. $\quad$ Tarso I con 5-6; tarsos III-IV con más de 5 artejos . .

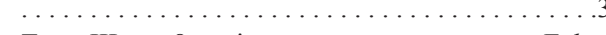

3. Tarso III con 8 artejos.............. Fakoa

-. Tarso III con $6-7$ artejos . . . . . . . . . . . . . .4

4. Escudo y terguitos libres completamente desarmados ............................ Angolypa Alguna de las áreas y de los terguitos provistos de espinas......................

5. Todas las áreas del escudo con 4 o más espinas. .... .................. Bibundina, Ivocoryphus Áreas I-III armadas con parejas de espinas . . . . . 66

6 Tarso III con 6 artejos; coxa IV con una espina o un grupo de 3-4 espinas.................... Tarso III con 7 artejos; coxa IV inerme, sólo granulosa..............................

\section{Género Chilon Sørensen 1896}

\section{6}

Especie típica. Chilon robustus Sørensen

Sinónimos: Acanthocoryphus Roewer 1953, Metachilon Roewer 1923, Monorhabdium Loman 1902, Parachilon Roewer 1923, Tsadsea Roewer 1935, Parachilon Roewer 1940, Sangalkamia Roewer 1953, Villersiella Roewer 1953, todos propuestos por Starȩga (1992), junto con Bindercola Roewer 1935 y Kobacoryphus Roewer 1961.

Diagnosis: Escudo con pares de espinas medias en las áreas I-III. Coxa IV armada con una robusta espina o un grupo de 3-4 dientes laterodorsales. Tarso I con 5, distitarso II con 3, tarso III con 6 artejos. (Sørensen 1896, Roewer 1935).

Distribución: África occidental y Golfo de Guinea. Las dos especies más repartidas, Chilon robustus Sørensen 1896 y Chilon scaber Sørensen 1896, se extienden desde Costa de Marfil hasta el lago Chad y la parte occidental de la R.D. del Congo; fuera de este centro están Chilon villiersi (Roewer 1953) de Senegal y Chilon salebrosus (Karsch 1879) de Cabinda.

Comentarios: Stareçga (1992) redefine fácticamente el género, sin aportar descripción ni figuras, al proponer numerosas sinonimias (incluso de especies descritas en otras subfamilias) e incluir las especies de seis géneros. Siguiendo su opinión, y a partir de la información publicada, no es posible una diagnosis más precisa para el género. La especie típica es Chilon robustus, con la que Stareçga (1992) sinonimiza hasta nueve especies nominales (una de ellas, la única del género típico de la "subfamilia" Tsadseinae) basándose en la similar morfología genital. Sin embargo, dos de estas reubicaciones en Chilon por Stareçga (1992) difícilmente pueden aceptarse: Bindercola albatra Roewer 1935 (Polycoryphinae), una especie completamente desarmada salvo por un par de tubérculos en el terguito libre II y con las coxas IV lisas; y Kobacoryphus royi Roewer 1961 (Polycoryphinae) por tener 6 artejos en el tarso I y 7 en el tarso III, y un pene diferentemente modelado (observación inédita).

\section{Clave abreviada de las especies del género Chilon:}

1. Área IV del escudo desarmada; terguito libre I con $0-1$ espinas $\ldots \ldots \ldots \ldots \ldots \ldots \ldots \ldots \ldots \ldots \ldots \ldots$

-. Área IV con 2 espinas medias; terguito libre I con 4 o más espinas ............... Chilon spp.

2. Escudo con orla blanca lateral y posterior. Patas muy largas $(\mathrm{PII} /$ cuerpo $>8) \ldots \ldots$. . . . Chilon cinctus

-. Escudo sin orla blanca. Patas más cortas (PII/cuerpo

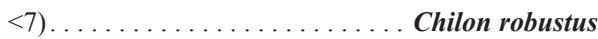


Chilon robustus Sørensen 1896

(Figs. 2, 12)

Sinónimos: Monorhabdium singulare Loman 1902, Chilon armatus Roewer 1912, Chilon ferrugineus Roewer 1912, Monorhabdium echinatum Roewer 1912, Chilon atroluteus Roewer 1916, Tsadsea picta Roewer 1935, Parachilon bistriatus Roewer 1940, Parachilon bicolor Roewer 1942, todos propuestos por Starȩga (1992).

\section{Recopilación bibliográfica:}

1896 Sørensen. Chilon robustus (p.188): s/loc. (Camerún); Kitta (= Kita, Camerún).

1923 Roewer. Chilon robustus (p.278): s/loc. (Camerún); Bibundi (= Idenao, Camerún). Metachilon armatus (p.280): Bouroukrou (Costa de Marfil). Parachilon ferrugineus (p.280): s/loc (Togo); Sekondi (Ghana). Parachilon atroluteus (p.281): Buea (Camerún). Monorhabdium singulare (p.281): Jaunde (= Yaoundé, Camerún). Monorhabdium echinatum (p.281): Old Calabar (= Calabar, Nigeria); Benin Flußufer (= Desembocadura de Río Benin, Benin); Costa de Marfil.

1927 Roewer. Chilon robustus (p.364): Basilé, 400-660m (Isla de Bioko, Guinea Ecuatorial); Musola (Isla de Bioko, Guinea Ecuatorial); Baja de S.Carlos (= Luba, Isla de Bioko, Guinea Ecuatorial). Monorhabdium echinatum (p.364): N’kogo (= ¿?, Gabón).

1935 Roewer. Monorhabdium singulare (p.56): Jaunde (= Yaoundé, Camerún). Monorhabdium echinatum (p.56): Old Calabar (= Calabar, Nigeria); Benin Flußufer (= Desembocadura de Río Benin, Benin); Costa de Marfil. Chilon robustus (p.57): Bibundi (Camerún); Edea (= Edéa, Camerún); Fernando Póo (Isla de Bioko, Guinea Ecuatorial). Parachilon ferrugineus (p.58): Togo; Sekondi (Ghana). Parachilon atroluteus (p.58): Buea (Camerún). Metachilon armatus (p.280): Bouroukrou (Costa de Marfil). Tsadsea picta (p.117): südl.des Tsadsees (= al sur del Lago Chad, Camerún).
1940 Roewer. Parachilon bistriatus (p.10): Edea (= Edéa, Camerún).

1942Roewer.Parachilonbicolor (p.245): Musola (Isla de Bioko, Guinea Ecuatorial).

1965 Lawrence. Monorhabdium singulare (p.804): Lamto (Costa de Marfil); Soubré, Niapoyo (Costa de Marfil).

Material estudiado: 1 , $\mathrm{ZUPV} / 2005, \mathrm{R}$. Congüe. 1Q, ZUPV/2016, PNMA: Monte Alén, vertiente NW. 1q, ZUPV/2026, PNMA: trayecto al Itinerario Pedagógico. 1' 9 , ZUPV/2036, PNMA: Ayene. $1 \sigma^{\nearrow}+2$, ZUPV/2045, R. Motora: $1 \mathrm{~km}$ al Este del puente.

Descripción: Coloración (Fig. 2A). Cuerpo amarillo, borde lateral del escudo con una reticulación oscura que se intensifica en la parte posterior; áreas I y II reticuladas en negro; áreas III a V, salvo la zona media, negras, al igual que los bordes laterales y posterior del escudo, formando en el escudo dorsal dos manchas negras bien diferenciadas. Mitad posterior del escudo bordeado por una línea blanquecina. Terguitos libres reticulados en gris, dejando una zona central más clara. Espinas dorsales y opérculo anal negros. Ventralmente, las coxas y los esternitos tienen un fondo amarillo, reticulado en oscuro; esternitos II-III con una mancha central de forma lanceolada.

Cara dorsal (Fig. 12A-B). Tubérculo ocular con dos pequeños dientes dorsales. Borde delantero del carapacho con una fila de gránulos. Longitud relativa de los procesos frontales, 12121. Áreas I-III con un par central de fuertes espinas; área IV desarmada; área V con una fila de 5-6 espinas, donde la espina o el par central tienen mayor desarrollo. Terguito libre I con una espina media, terguito libre II con un par central de espinas y terguito libre III con tres espinas. Además, todos los terguitos libres I-III tienen una fila de gránulos diminutos y un par de espinas marginales. Coxa IV con una gruesa espina dorsal. Cara ventral. Coxas uniformemente granulosas y finamente reticuladas en gris; coxa I con un reticulado más intenso y dos filas de tubérculos; espiráculos cubiertos por 2-3 puentes quitinosos. 


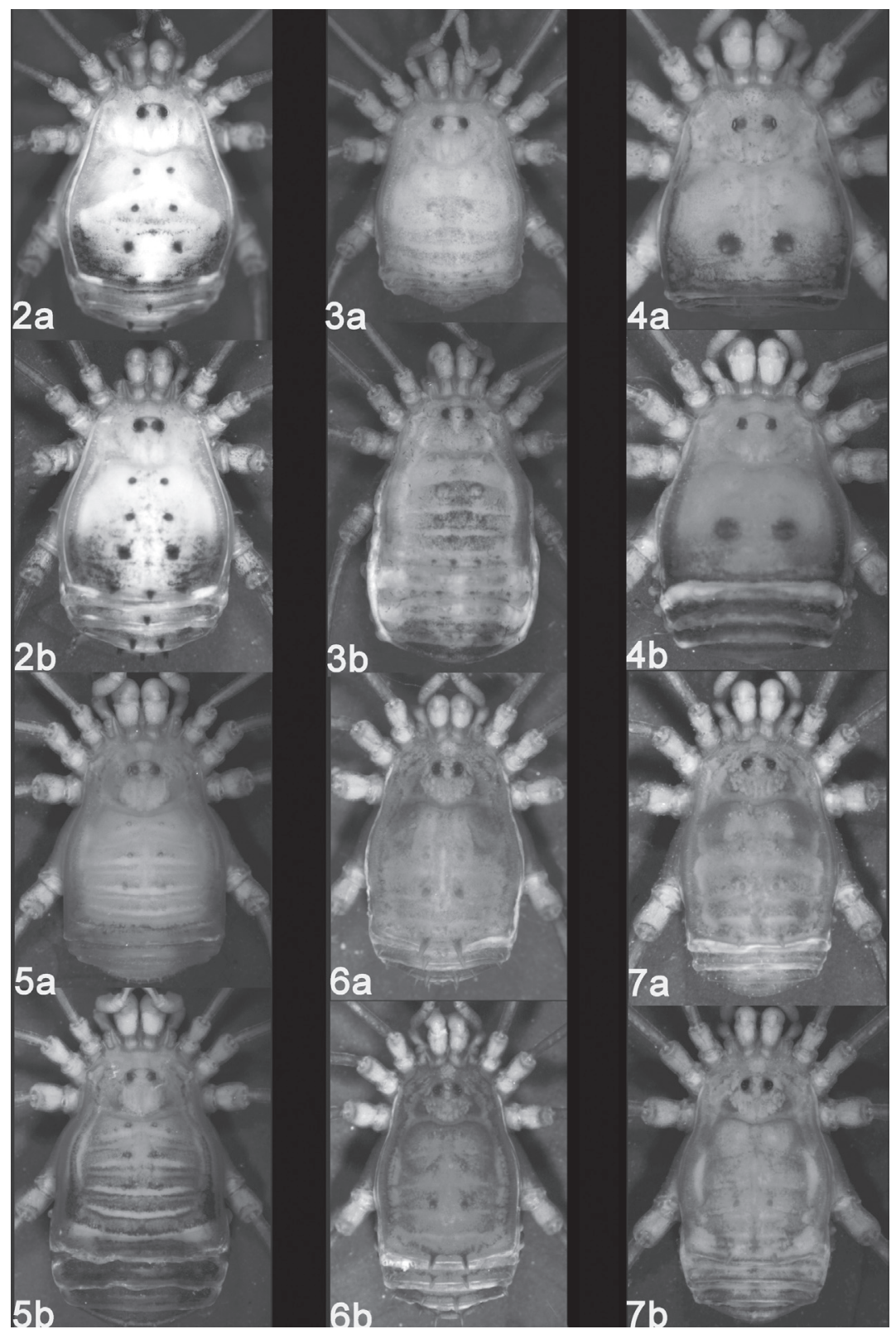

Figs. 2-7. Vistas dorsales del macho y la hembra de: 2. Chilon robustus Sørensen 1896, ZUPV/2045: A, Ơ; B, O. 3. Mbinia

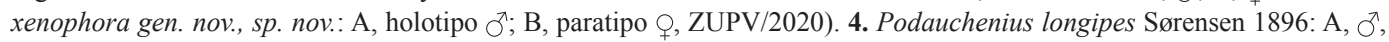
ZUPV/2008; B, @, ZUPV/2015). 5. Rhabdopygus funilignorum sp. nov: A, holotipo o'; B, paratipo Q, ZUPV/2038. 6. Seuthessus coriscanus sp. nov: A, holotipo ơ'; B, paratipo o, ZUPV/2079. 7. Seuthes inermis sp. nov. A, holotipo O'; B, paratipo o, ZUPV/2035).

Figs. 2-7. Dorsal views of the male and the female of: 2. Chilon robustus Sørensen 1896, ZUPV/2045: A, O’; B, o. 3. Mbinia xenophora gen. nov., sp. nov: A, holotype ơ; B, paratype o, ZUPV/2020). 4. Podauchenius longipes Sørensen 1896: A, o', ZUPV/2008; B, @, ZUPV/2015). 5. Rhabdopygus funilignorum sp. nov.: A, holotype ơ'; B, paratype o, ZUPV/2038. 6. Seuthessus coriscanus sp. nov: A, holotype ơ; B, paratype o, ZUPV/2079. 7. Seuthes inermis sp. nov. A, holotype O; B, paratype o, ZUPV/2035). 


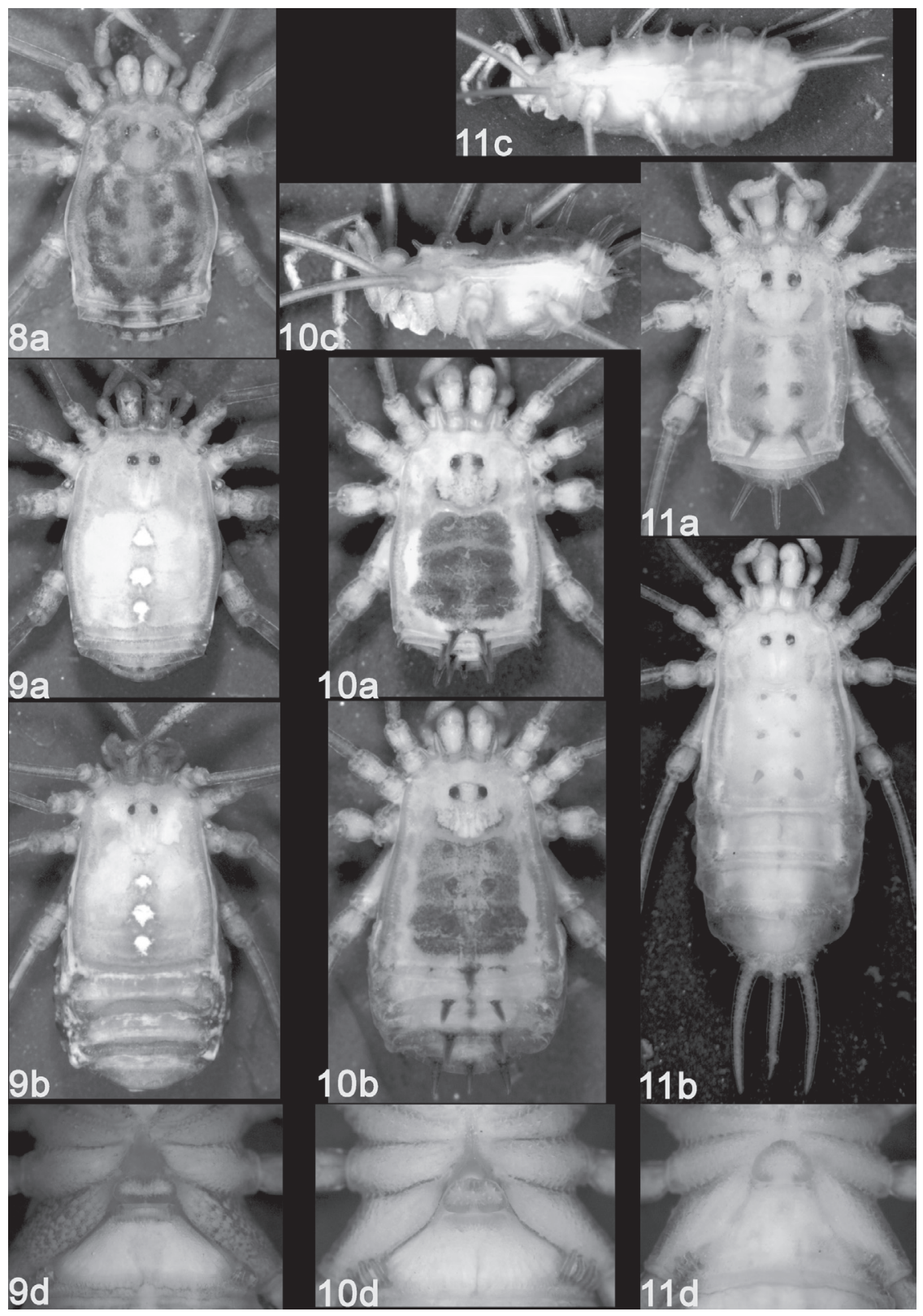

Figs. 8-11. Vistas externas de las siguientes especies: 8. Binderia longipes sp. nov., : holotipo ${ }^{\nearrow}$, dorsal. 9. Ayenea trimaculata gen. nov., sp. nov.: A, holotipo ơ, dorsal; B-C, paratipo @, ZUPV/2052: B, dorsal; C, opérculo genital. 10. Niefanga spinosa gen. nov., sp. nov.: A, holotipo ơ, dorsal; B-D, paratipo o, ZUPV/2021: B, dorsal, C, opérculo genital; D, lateral. 11. Montalenia forficula gen. nov., sp. nov.: A, holotipo $\mathrm{O}^{\top}$, dorsal; B-D, paratipo $\mathrm{O}, \mathrm{ZUPV} / 2012$ : B, dorsal, C, opérculo genital; D, lateral.

Figs. 8-11. External views of the following species: 8. Binderia longipes sp. nov., : holotype ${ }^{\top}$, dorsal. 9. Ayenea trimaculata gen. nov., sp. nov.: A, holotype $\sigma^{\nearrow}$, dorsal; B-C, paratype $\bigcirc$, ZUPV/2052: B, dorsal; C, genital operculum. 10. Niefanga spinosa gen. nov., sp. nov.: A, holotype $\sigma^{\top}$, dorsal; B-D, paratype o, ZUPV/2021: B, dorsal, C, genital operculum; D, lateral. 11. Montalenia forficula gen. nov., sp. nov: A, holotype $\sigma^{\top}$, dorsal; B-D, paratype , ZUPV/2012: B, dorsal, C, genital operculum; D, lateral. 
Pedipalpos (Fig. 12C). Negruzcos. Trocánter con un par de dientes ventrales; fémur con una hilera ventral de 15 o más dentículos y con gránulos dorsales, con espina mesoapical; patela con dos gránulos dorsales; tibia con una hilera mesal de tres dientes y dos espinas (en posición $2^{\mathrm{a}}$ y $5^{\mathrm{a}}$ ) y una ectal de tres dientes y una espina (en posición $3^{\mathrm{a}}$ ); tarso con dos largas espinas a cada lado. Quelíceros. Color amarillo pálido con suave reticulación grisácea. Joroba del artejo proximal con un pequeño diente en el lado externo. Patas. Trocánteres amarillo pálido, patelas negras, resto uniformemente oscuras. Fórmula tarsal: 5, 9-10 (3), 6, 6-7.

Pene (Fig. 12D-E). Tronco uniformemente delgado, cuello algo engrosado. Cabeza penial cordiforme, recorrida lateralmente por una carena traslúcida y con dos engrosamientos espinosos, separados por un surco medio, rodeando el glande. Lado ventral con tres pares de pequeñas sedas, dos frontales apuntando a sus parejas y el tercero sobre los abultamientos laterales. Lateral con tres sedas foliadas grandes y alineadas dorsoventralmente. Dorsal con tres pares de pequeñas sedas, dos apicales y el tercero flanqueando el glande y apuntando hacia abajo.

Hembra (Fig. 2B). Muy similar al macho, con el opistosoma más distendido. La coloración de la zona posterior al opérculo genital es diferente, con una zona central ancha y oscura (y no una línea negra media como en los machos).

Comentarios: Chilon robustus se diferencia fácilmente de otras especies del género por tener el área IV del escudo desarmada y con, a lo más, una espina media en el primer terguito libre; Chilon cinctus, que comparte dichos elementos diagnósticos, se diferencia por presentar una conspicua orla blanca que rodea lateral y posteriormente el escudo dorsal y patas bastante más largas. Sin embargo, la revalidación de Chilon undulatus propuesta por Bauer \& Prieto (2009) modifica este escenario: ambas especies presentan penes similares pero claramente distintos, el de Chilon undulatus tiene el tronco del pene dorsoventralmente ensanchado en su ápice y acabado en un nítido cuello y una cabeza penial más ancha que larga.

\section{English diagnosis of new taxon}

Mbinia gen. nov.

(Type species, Mbinia xenophora sp. nov.)

Member of the subfamily Erecinae characterized by: abdominal shield with undivided area I, areas I-III with pairs of spines, area $\mathrm{V}$ and free tergites I-III with rows of spines; palpal femur without apicomedial spines; coxa IV unarmed; penis spatula-shaped, with distal part of the trunk enlarged and penis head with a frontal trilobation.

\section{Género Mbinia nov.}

Especie típica: Mbinia xenophora sp. nov.

Etimología: A partir del topónimo Mbini, palabra fang que designa la Región Continental de Guinea Ecuatorial. Género gramatical, femenino.

Diagnosis: Miembro de la subfamilia Erecinae distinguible por: escudo abdominal con área I entera, áreas I-III con pares de espinas, y área $\mathrm{V}$ y terguitos libres I-III con filas de espinas; fémur del pedipalpo sin espinas mesoapicales; coxa IV inerme; fórmula tarsal: 6,15 (3), 7, 8; pene espatuliforme, con parte distal del tronco muy gruesa continua con una cabeza penial trilobulada frontalmente.

Comentarios: La absoluta falta de datos sobre la validez de los caracteres diagnósticos a nivel genérico y sobre la morfología del aparato genital, sólo paliada por Kauri (1985) para Ereca y otros géneros próximos de Africa oriental, complica la asignación genérica de esta nueva especie. Como se ha señalado anteriormente, la acumulación de muchas especies en el género Chilon, sin redefinición del mismo, propuesta por Starȩga (1992) resulta excesiva, como demuestran Bauer \& Prieto (2009) al revalidar Chilon undulatus, e impide establecer sus límites. La decisión de erigir un nuevo género se basa, fundamentalmente, en 


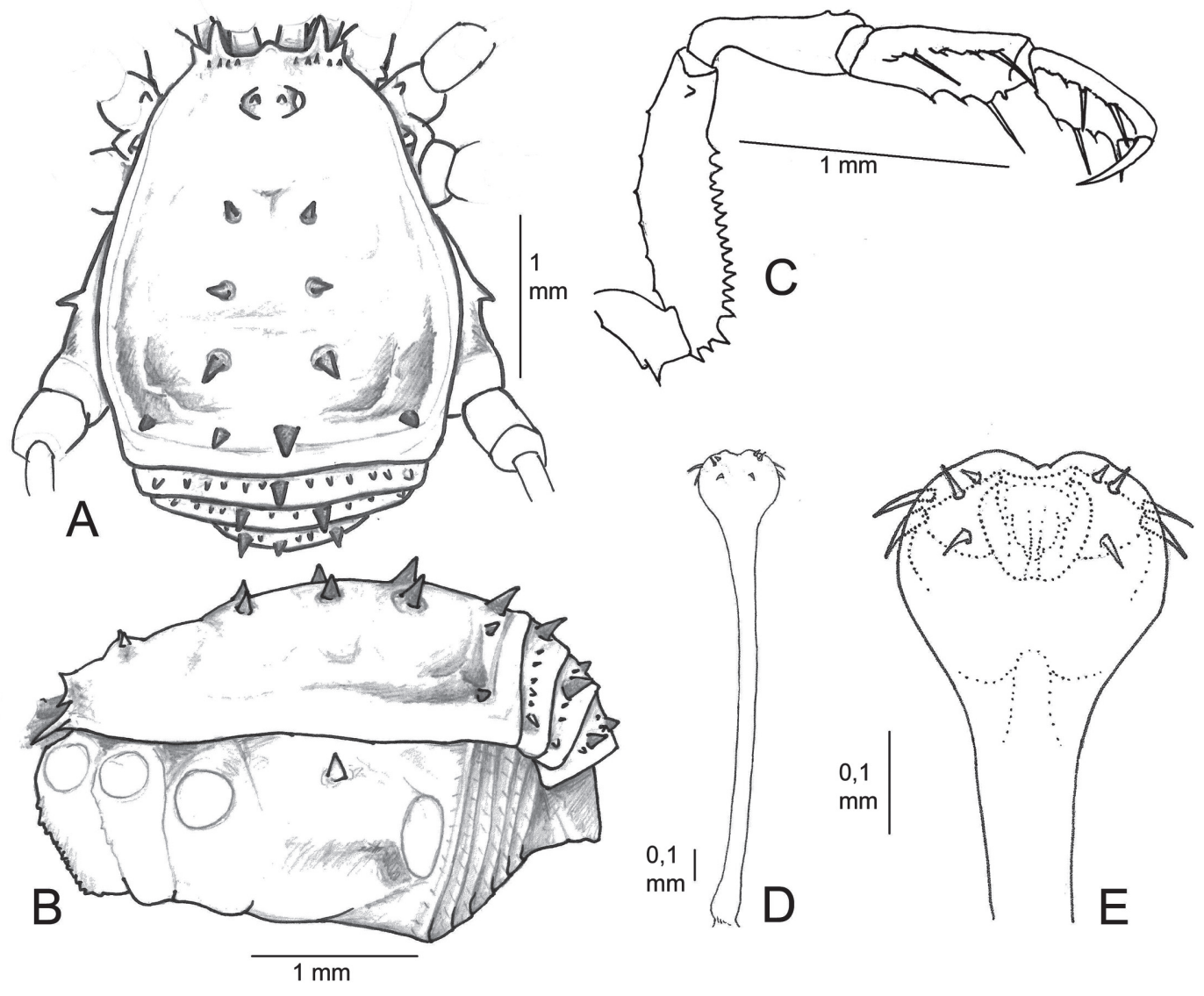

Fig. 12. Chilon robustus Sørensen 1896. ð๐ (ZUPV/2045). A, dorsal; B, lateral; C, pedipalpo izquierdo (mesal); D, pene; E, cabeza penial (ventral).

Fig. 12. Chilon robustus Sørensen 1896. Oో (ZUPV/2045). A, dorsal; B, lateral; C, left palp (mesal); D, penis; E, penial head (ventral).

la diferente construcción del pene respecto del de las dos especies del género Chilon conocidas en este sentido, el cual presenta una parte distal (cabeza penial) separada del tronco por un cuello, con perfil acorazonado y una hilera transversal de tres espinas en el lateral por su parte más ancha. Otros caracteres discrepantes son la ausencia de espinas en las coxas IV y la fórmula tarsal.

\section{English diagnosis of new taxon}

Mbinia xenophora sp. nov.

(Holotype: MNCN, Madrid; type locality, Monte Alén National Park, Equatorial Guinea). Figs. 3, 13. Measurements in table 3.

Body yellowish, finely reticulated in brown colour, darker in areas III-IV, their lateral edges and free tergites; coxae IV blackish; ventral 


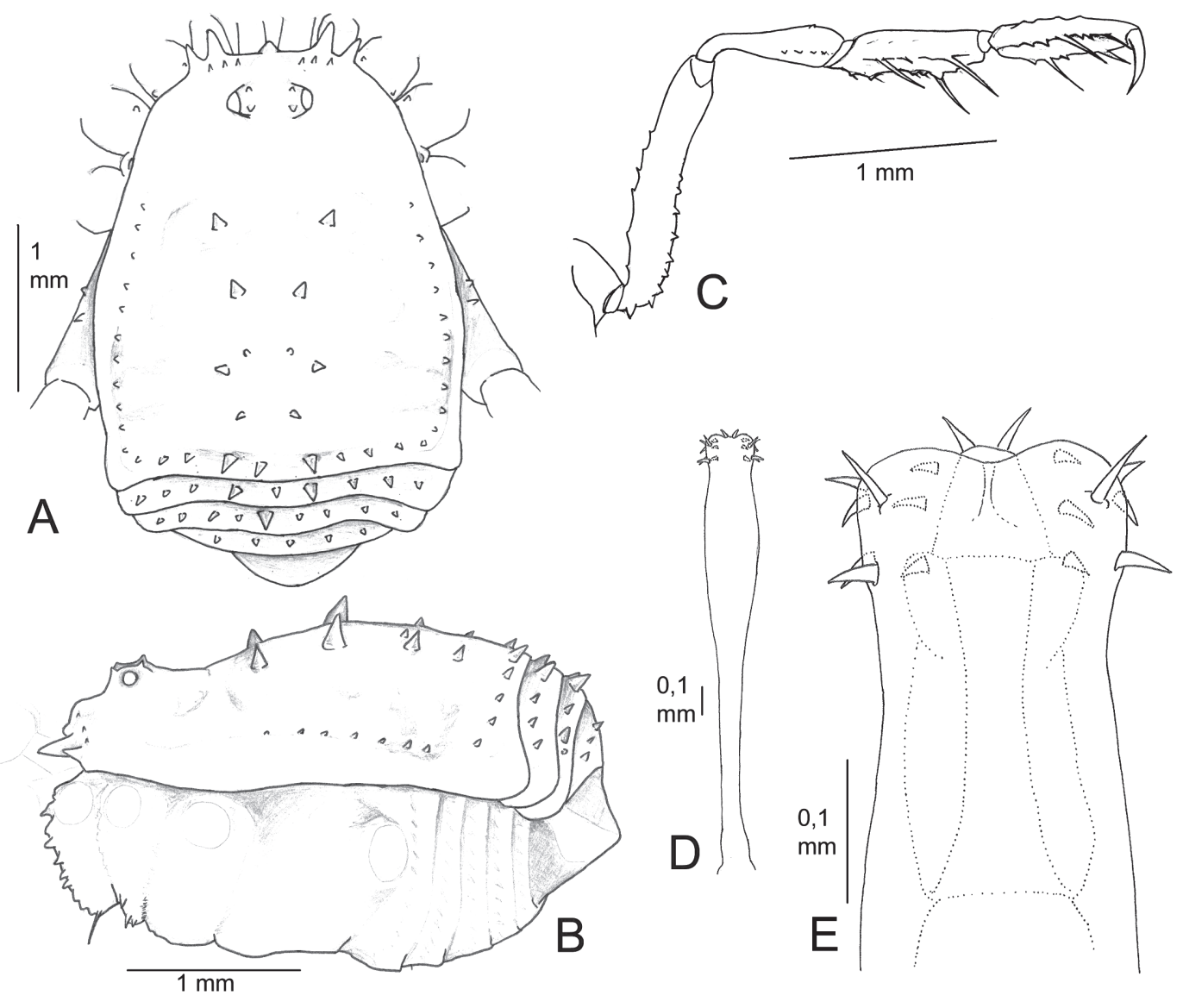

Fig. 13. Mbinia xenophora gen. \& sp. nov. Holotipo $\sigma^{7}$. A, dorsal; B, lateral; C, pedipalpo izquierdo (mesal); D, pene; E, cabeza penial (ventral).

Fig. 13. Mbinia xenophora gen. nov., sp. nov. Holotype ${ }^{\top}$. A, dorsal; B, lateral; C, left palp (mesal); D, penis; E, penial head (ventral).

side yellowish, with darkened coxae IV and sternites, and blackish anal sclerites. Relative length of frontal processes, 24142. Areas I to III with pairs of spines; in addition, areas I, III and IV present paramedian pairs of grains; area $\mathrm{V}$ and free tergites with a row of small spines on each, the paramedian pair larger. Spiracles partially concealed by short cuticular processes. Palpal femur with a ventral row with nine decreasing denticles. Legs yellowish, long and thin, with whitish tarsi; tarsal formula: 6 ,
15 (3), 7, 8. Penial head flattened, with the following setae disposition: three ventral pairs in two parallel lines, two lateral pairs, a dorsal pair on lateral lobes and a frontal pair on the central lobe; glans cone-shaped.

\section{Mbinia xenophora sp. nov.}

(Figs. 3, 13)

Localidad típica: PNMA: Monte Alén, vertiente NW; 32NPG48. 
Holotipo: Or (MNCN/20.02/17074, exZUPV/2014), PNMA: Monte Alén, vertiente NW. Paratipos: 1q, ZUPV/2020, PNMA: trayecto al Itinerario Pedagógico.

Etimología: El nombre alude a la presencia, probablemente casual, de organismos extraños sobre los dos ejemplares encontrados, el macho con un ácaro unido a la parte posterior del escudo por un denso retículo sedoso mientras que la hembra presenta adheridas al cuerpo numerosas cápsulas submicroscópicas negruzcas de dos formas, una globular y otra fusiforme y tabicada.

Descripción: Coloración (Fig. 3A). Cuerpo amarillento reticulado en oscuro, más intensamente en las áreas III y IV y borde del escudo correspondiente a esa zona. Terguitos libres reticulados en oscuro, tanto como las áreas III y IV. Cara ventral amarilla, con las coxas IV y los esternitos algo más oscurecidos. Dorso de las coxas IV y opérculo anal muy oscuros.

Cara dorsal (Fig. 13A-B). Tubérculo ocular más ancho que largo, más próximo al borde frontal, con un par de gránulos junto a cada ojo. Fila de pequeños gránulos en el borde delantero del carapacho. Longitud relativa de los procesos frontales, 24142. Áreas I a III con pares de espinas, las del área II más grandes y próximas entre sí; además, las áreas I, III y IV presentan pares de gránulos en posición más central; área V y terguito libre I con una fila de pequeñas espinas, el par central más grande; terguitos libres II-III con una fila de pequeñas espinas, siendo la central del terguito libre II más grande. Fila de gránulos en el borde lateral del escudo. Cara ventral. Coxa I con tres filas de tubérculos, la más anterior es corta y compacta, la fila media está formada por 6-7 tubérculos mayores con largas sedas, y los gránulos de la fila posterior son muy reducidos; coxas II-IV finamente granuladas; cara laterodorsal de las coxas IV con tres dientes. Espiráculos traqueales parcialmente cubiertos por cortas prolongaciones cuticulares.

Pedipalpos (Fig. 13C). Trocánter con una espina ventral; fémur con una fila ventral de
9 dentículos decrecientes y granuloso dorsalmente, sin espina mesoapical; patela granulosa; tibia con una fila mesal de dientes y dos espinas, basal y apical y una fila ectal de cinco dientes, una espina y un diente apical; tarso con dos largas espinas y una fila de dientecillos a cada lado. Quelíceros. Artejo proximal con unos pequeños gránulos en el borde posterior de la joroba, reticulado en negro; artejo medio más amarillo, con sedas dispersas. Patas. Largas y delgadas, con los tarsos blanquecinos. Fórmula tarsal: 6, 15 (3), 7, 8.

Pene (Fig. 13D-E). Longitud, 1.6mm. Tronco con base algo engrosada $(0.1 \mathrm{~mm})$ y mitad apical progresivamente engrosada $(0.2 \mathrm{~mm})$ y luego algo adelgazada, formando un ancho cuello, dando a todo el conjunto un perfil espatuliforme. Cabeza penial dorsoventralmente aplanada respecto de la parte distal del tronco y casi tan ancha, frontalmente trilobulada, bien provista de sedas con la siguiente disposición: ventralmente, tres sedas en dos líneas paralelas; lateralmente, dos pares a cada lado; dorsalmente, una seda en el centro de los lóbulos laterales; y frontalmente, un par de sedas sobre el lóbulo medio. Glande troncocónico.

Hembra (Fig. 3B). Similar al macho, aunque de mayor tamaño. El tarso de la pata I sólo tiene cinco artejos.

\section{Subfamilia HYPOXESTINAE Roewer 1935}

Sólo tres de los 37 géneros habitan en la Región Oriental (sur de Asia e Indochina); el resto son propios de la Región Etiópica, y se distribuyen por África Oriental y Central; únicamente Rhabdopygata mossambica Roewer 1935 se encuentra en Africa Meridional. En la región del golfo de Guinea hay diez géneros (Roewer 1927, 1935, 1940, 1952; Sørensen 1896): Adamauna Roewer 1935, Dongila Roewer 1927, Findia Roewer 1927, Musola Roewer 1927, Nkogoa Roewer 1927, Podauchenius Sørensen 1896 y Podaucheniellus Roewer 1927 son monotípicos e Hypoxestinus Roewer 1927 tiene dos especies. Viglua Roewer 1940 alberga cuatro especies de Angola, mientras que Rhabdopygus Roewer 1912, incluye cinco, 
sin contar a Rhabdopygus maculatus Roewer 1935 (ver más abajo).

\section{Clave abreviada para los géneros del Golfo de Guinea:}

1. Distitarso II con 4 o más artejosAdamauna y Musola

-. Distitarso II con 3 artejos . . . . . . . . . . . 2

2. Tarso III con $8-9$ artejos . . . . . . . . . . . . 3

-. Tarso III con 6-7 artejos . . . . . . . . . . . . . .4

3. Tarso II con 10-12 artejos; Tarso IV con 9 artejos .. .................... Podaucheniellus Tarso II con más de 14 artejos; Tarso IV con más de

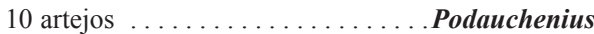

4. Escudo completamente desarmado.............. Findia e Hypoxestinus Alguna de las áreas del escudo con espinas o

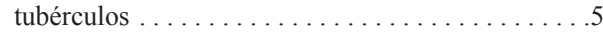

5. Área $\mathrm{V}$ y terguito libre $\mathrm{I}$ desarmados $\ldots \ldots \ldots \ldots$ ..................... Viglua y Nkogoa

-. Área $\mathrm{V}$ y terguitos libres I-III armados . . . . . . . .6

6. Área $\mathrm{V}$ con una y terguitos libres con 1-3 espinas... $\ldots \ldots \ldots \ldots \ldots \ldots \ldots \ldots \ldots \ldots \ldots \ldots \ldots \ldots \ldots$ Dongila Área V y terguitos libres con filas de tubérculos o gránulos.

Rhabdopygus

\section{Género Podauchenius Sørensen 1896}

Especie típica: Podauchenius longipes Sørensen 1896.

Diagnosis: Área I con surco medio; área III con dos grandes espinas; áreas restantes y terguitos libres desarmados. Fémur del pedipalpo con dos espinas en la zona mesoapical. Coxa IV desarmada. Patas muy largas. Fórmula tarsal: todos con más de seis (Roewer 1935).

Comentarios: Género monotípico, fácilmente reconocible por las dos grandes espinas del área III, la gran longitud de las patas (en los machos) y la división del área I por un surco medio, característica frecuente en los géneros de África oriental pero muy infrecuente en los del Golfo de Guinea.

\section{Podauchenius longipes Sørensen 1896} (Figs. 4, 14)

\section{Recopilación bibliográfica:}

1896 Sørensen. Podauchenius longipes (p.201):

Kamerun (= Camerún).
1912 Roewer. Podauchenius longipes (p.85): Johann-Albrechtshöhe (= Estación de ferrocarril de Kumba, $4^{\circ} 35^{\prime} \mathrm{N} 9^{\circ} 25^{\prime} \mathrm{E}$, Camerún).

1923 Roewer. Podauchenius longipes (p.285): Kamerun, genauer Fundort? (= s/loc., Camerún); Johann-Albrechtshöhe.

1927 Roewer. Podauchenius longipes (p.367): Fernan Vaz (= Laguna Nkomi, Gabón).

1935 Roewer. Podauchenius longipes (p.31): Johann-Albrechtshöhe (Camerún); Fernan Vaz (Gabón); Haut Vété-Mato (R.D. Congo); Homi (R.D. Congo); Elisabethville (= Lubumbashi, R.D. Congo).

1992 Starȩga. Podauchenius longipes (p.315): recopilación de las localidades anteriores.

Material estudiado: $10^{\top}, \mathrm{ZUPV} / 2008$, PNMA: Monte Alen. 2ᄋ, ZUPV/2015, PNMA: Monte Alen, vert.NW. 10', ZUPV/2050, R. Motora (Mitong): $1 \mathrm{~km}$ al E.

Descripción: Coloración (Fig. 4A). Variable, desde pardo-verdoso con zonas amarillo pálido (espinas, trocánteres, pedipalpos) hasta orín con suave reticulación oscura, más intensa en los bordes laterales y posteriores del escudo, así como en las espinas del terguito libre III.

Cara dorsal (Fig. 14A-B). Tubérculo ocular bajo, ovalado, bien centrado en el carapacho, con dos gránulos diminutos. Longitud relativa de los procesos frontales, 26362. Área I con dos pares de pequeños tubérculos; áreas II y IV con un par de pequeños tubérculos centrales; área III con dos grandes espinas romas; área $\mathrm{V}$, terguitos libres y borde lateral del escudo con una fila de gránulos. Cara ventral. Coxa I con 5-6 tubérculos largos y agudos en la primera fila, fila central con 6-7 tubérculos cónicos y robustos, y fila posterior con numerosos gránulos pequeños; coxas II a IV granulosas. Espiráculos completamente visibles, pero se aprecia un conjunto de tubérculos en la esquina coxo-esternal. Esternitos provistos de hileras de pequeños gránulos.

Pedipalpos (Fig. 14C). Trocánter con una fuerte espina ventral; fémur ventralmente dentado en toda su longitud, dorsalmente con una 


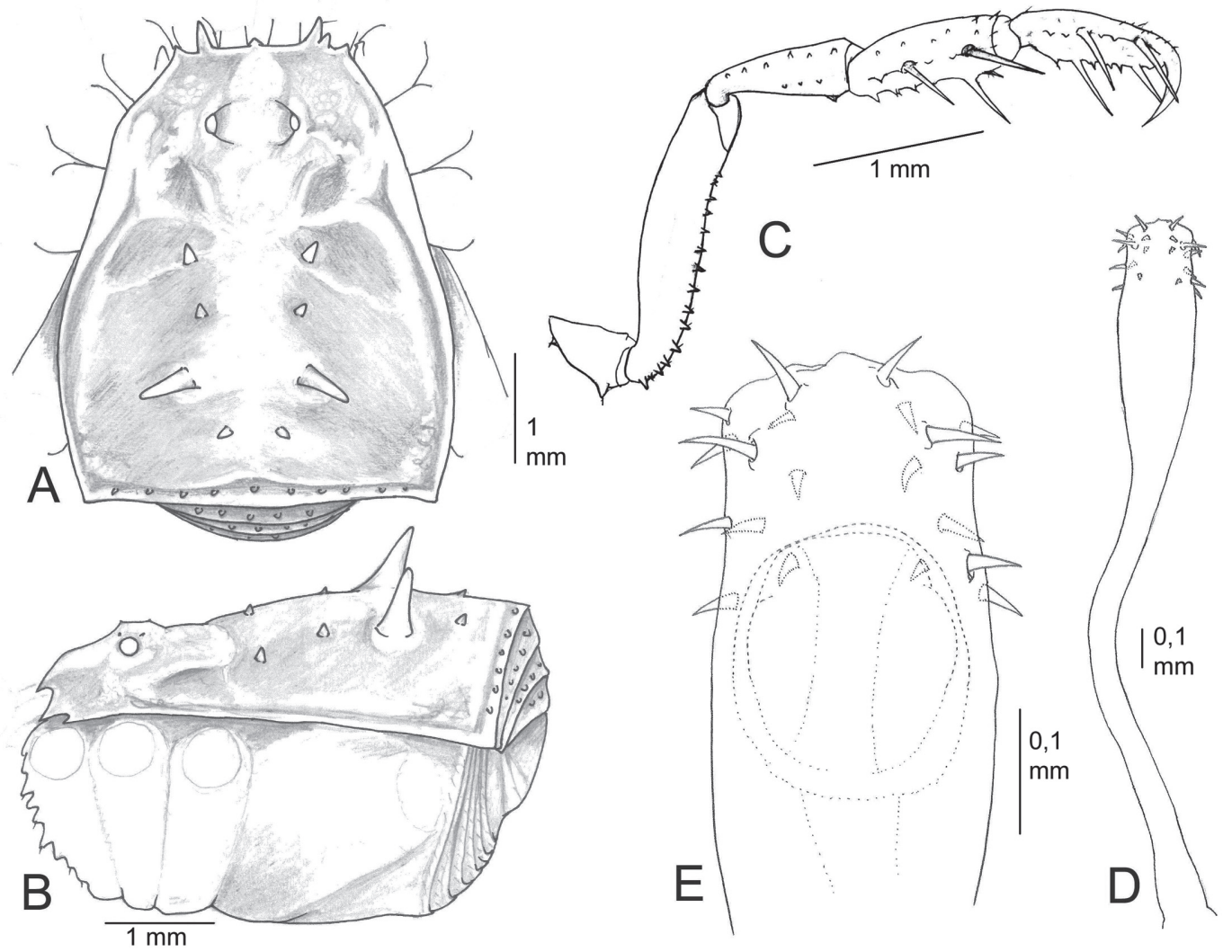

Fig. 14. Podauchenius longipes Sørensen 1896. O`(A-C, ZUPV/2050; D-E, ZUPV/2008). A, dorsal; B, lateral; C, pedipalpo izquierdo (mesal); D, pene; E, cabeza penial (ventral).

Fig. 14. Podauchenius longipes Sørensen 1896. O` (A-C, ZUPV/2050; D-E, ZUPV/2008). A, dorsal; B, lateral; C, left palp (mesal); D, penis; E, penial head (ventral).

fila de gránulos; patela con una fila dorsal de gránulos, y con 3-4 espinitas en la zona ventroapical, sin espina mesoapical; tibia con dos largas espinas ventromesales y con una larga espina ventrolateral apical. Tarso a cada lado con dos espinas. Todo el pedipalpo tiene un aspecto granuloso, debido a los pequeños dientecillos que lo recubren. Quelíceros. Joroba del artejo proximal con 2-3 dentículos apicales. Patas. Lisas, muy largas y finas, especialmente la pata II. Color oscuro con los tarsos y extremo apical de la tibia II blanquecinos. Fórmula tarsal: 7-8, 16 (3), 9-10, 12.
Pene (Fig. 14D-E). Tronco con base apenas engrosada, luego regularmente esbelto y tercio distal fuertemente engrosado $(0.2 \mathrm{~mm})$, sin cuello apreciable, dando un perfil espatuliforme a todo el conjunto. Cabeza penial vagamente apuntada, con glande muy separado del borde frontal y numerosas sedas: ventralmente, dos pares de largas sedas, uno subdistal y otro frontal; lateralmente, dos pares a cada lado, uno al nivel del glande y el otro subdistal; dorsalmente, cuatro pares, regularmente distanciados y formando dos líneas (salvo un par casi lateral). 
Hembra (Fig. 4B). Cuerpo anaranjado, con marcada reticulación oscura y espinas también oscuras. La forma del cuerpo y armadura son muy similares a las del macho, y la longitud de las patas es mucho menor, especialmente la de las patas II. Fórmula tarsal, diferente a la del macho: 6, 10-14 (3), 8-9, 8-11.

\section{Género Rhabdopygus Roewer 1912}

\section{Especie típica: Rhabdopygus fuscus Roewer 1912}

Diagnosis: Tubérculo ocular con un par de espinas o granuloso. Área I del escudo sin surco medio longitudinal; áreas II y III cada una con un par de tubérculos; áreas I y V, así como terguitos libres I-II del opistosoma, desarmados; terguito libre III con un par de espinas. Coxa IV lateralmente sin una espina gruesa. Fémur del pedipalpo con una o dos espinas mesoapicales. Fórmula tarsal: $6,>6$ (3), $\geq 6,>6$ (Roewer 1935).

Distribución: Rhabdopygus fuscus es la especie más extendida: Guinea-Bissau, Camerún, Gabón, Congo y R.D. del Congo. De la R.D. del Congo se han descrito Rhabdopygus benoiti Kauri 1985 de Feshi, Rhabdopygus rugipalpis Roewer 1952 del Upemba National Park y Rhabdopygus termitarum Roewer 1951 del Plateau de Langa. Finalmente Rhabdopygus robustus Lawrence 1957 de Cacolo (NO de Angola) y Rhabdopygus maculatus Roewer 1935 de Usambara (Tanzania) que no pertenecería a este género por la discrepante morfología penial, más similar a la de Erecinae que a la de Hypoxestinae (Bauer \& Prieto 2009).

\section{Clave de especies de Rhabdopygus (adaptada de Kauri 1985):}

1. Tubérculo ocular con un par de espinas o tubérculos

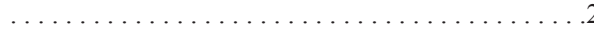

Tubérculo ocular sin espinas ni tubérculos, sólo granular......................6

2. Áreas del escudo granulosas y además con pares de tubérculos .............. "R." maculatus

-. Áreas del escudo prácticamente lisas . . . . . . . . . 3

3. Borde lateral del escudo con fila(s) de gránulos . . .4
-. Borde lateral del escudo sin fila de gránulos . . . . . 5

4. Terguito libre III con una fila de gruesos gránulos y un par de largas espinas ........R. rugipalpis Terguito libre III con una fila de gránulos y un par de pequeños tubérculos.......... "R." benoiti

5. Áreas I y IV lisas; tarso III con 6 artejos; color amarillo-rojizo. . . . . . . . . . . . . R. fuscus Área I con dos tubérculos, área IV con gránulos; tarso III con 7 artejos; color pardo a oliváceo ...... $\ldots \ldots \ldots \ldots \ldots \ldots \ldots$. funilignorum

6. Terguito libre III con una fila de pequeños gránulos, dos mayores. Cara dorsal pardo-negruzca y tinte verdoso, con manchas pardo-rojizas pareadas ...... $\ldots \ldots \ldots \ldots \ldots \ldots \ldots$. robustus

-. Terguito libre III con una fila de gránulos y un par de cuernos. Cara dorsal pardo-amarillenta . . . . . . . .

R. termitarum

\section{English diagnosis of new taxon}

Rhabdopygus funilignorum sp. nov. (Holotype: MNCN, Madrid; type locality, Monte Alén National Park, Equatorial Guinea). Figs. 5,15 . Measurements in table 3

Brown-reddish upper surface, with dark reticulation, lateral and back scutal edges lined by a dark stripe, areas I-IV with contrasting inner lighter zones, sternites and corona analis dark brown, coxa IV with a lighter stripe. Relative length of frontal processes, 36263. Frontal edge with 4-5 denticles on each side, ocularium sided by sparse denticles and armed by two spines. Areas I-III with a pair of separated paramedian tubercles flanked laterally by few granules, areas IV-V and free tergites I-III with a granule row on each, the third with a paramedian pair of larger granules. Coxa II with a dorsal protuberance. Spiracles unprotected, without tubercles on coxosternal corners. Palpal femur ventrally toothed, with a lateral granule row and two apicomedial teeth, patella with 2-3 small apicomedial teeth, tibia with two long spines on ventromedial edge. Legs robust, specially legs III and IV (with slightly curved femur), and brownish, with darker segment ends. Metatarsus III enlarged in males. Tarsal formula: 6, 10-12 (3), 7, 7. Penis trunk slender, with narrow basis, conspicuous neck, quadrangular head with five laterobasal pairs of hooked setae and two lateroapical pairs of very 
small setae; glans with a tongue-like piece and a terminal button.

Rhabdopygus funilignorum sp. nov.

(Figs. 5, 15)

Localidad típica: PNMA, Ayene: bosque primario, cabecera río, 32NPG48.

Holotipo: $\sigma^{7} \quad(\mathrm{MNCN} / 20.02 / 17075$, ex-ZUPV/2038). Paratipos: $2 \sigma^{\top}+5 q$, ZUPV/2038, recogidos con el holotipo. $10^{\top}$ $+1 '$, ZUPV/2034, Río Motora (Mitong): $3 \mathrm{~km}$ E. $1 \sigma^{\top}+5$,,$Z U P V / 2047$, Río Motora: $1 \mathrm{~km}$ E. $2 \sigma^{\top}, \mathrm{ZUPV} / 2006$, Río Congüe. $1 \sigma^{\top}+2 q$, ZUPV/2009, Monte Alén.
Etimología: El nombre alude a su frecuente presencia dentro de los segmentos huecos de lianas podridas, combinando las palabras latinas funis, cuerda y lignum, madera.

Diagnosis: Tubérculo ocular con un par de espinas; tarso III con 7 segmentos; área I con un par de tubérculos; área IV con una fila de gránulos.

Descripción: Coloración (Fig. 5A). Cara dorsal pardo-rojiza, con el carapacho reticulado en oscuro. Bordes laterales y posterior del escudo contorneados por una línea irregular negruzca; áreas I-IV con marcada reticulación oscura, dejando líneas claras entre las áreas y,
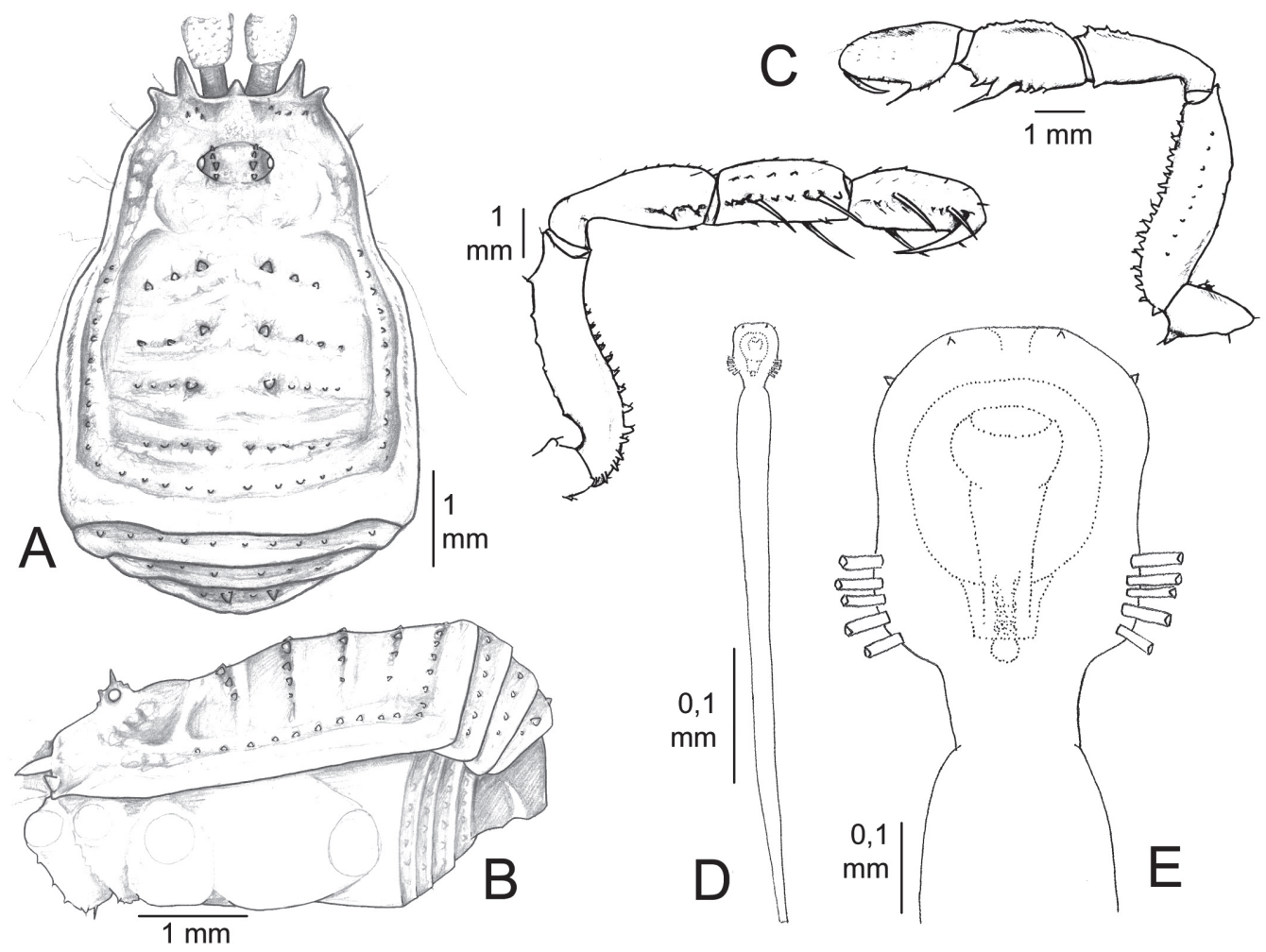

Fig. 15. Rhabdopygus funilignorum sp. nov. Holotipo $\mathrm{O}^{\top}$. A, dorsal; B, lateral; C, pedipalpo izquierdo (mesal y ectal); D, pene; E, cabeza penial (ventral).

Fig. 15. Rhabdopygus funilignorum sp. nov. Holotype ${ }^{\top}$. A, dorsal; B, lateral; C, left palp (mesal and ectal); D, penis; E, penial head (ventral). 
más nítidas, en el interior de éstas. Terguitos libres y opérculo anal con marcada reticulación negra. Coxa IV con una línea dorsal más clara. Cara ventral rojiza.

Cara dorsal (Fig. 15A-B). Tubérculo ocular ovalado, bien centrado dentro del carapacho, con ojos rodeados por 3-4 gránulos, destacando por su mayor tamaño el par situado sobre los ojos. Longitud relativa de los procesos frontales, 36263. Borde frontal a cada lado con hileras de 4-5 gránulos espinosos; lateral del carapacho con algunos gránulos puntiagudos dispersos, y un par de gránulos tras el tubérculo ocular. Borde lateral del escudo con una fila de gránulos diminutos. Áreas I-III con sendos pares de tubérculos paramedianos, bastante separados, flanqueados por cortas hileras laterales de gránulos, las posteriores más numerosas; áreas IV y V y terguitos libres I-III con una fila transversal de gránulos, los de las áreas más marcados; un par de gránulos del terguito libre III es algo más robusto que el resto. Coxa II con una gruesa protuberancia dorsal. Cara ventral. Coxa I con tres filas de tubérculos, la primera con 5-6 tubérculos puntiagudos que confluye donde acaba la fila intermedia, formada por 8-9 gruesos tubérculos; la última fila está formada por numerosos pequeños tubérculos. Resto de coxas granulosas. Espiráculos traqueales completamente visibles y desprotegidos, sin rastro de tubérculos en la esquina coxo-esternal. Esternitos con filas de gránulos. Opérculo anal con gránulos dispersos y una raya transversal central más clara.

Pedipalpos (Fig. 15C). Trocánter con una espina ventral y un diente dorsal; fémur ventralmente dentado en toda su longitud, con dos pequeños dientes mesoapicales y una fila lateral de gránulos; patela con 2-3 pequeños dientes mesoapicales; tibia ventromesalmente con: 2 dientes-1 espina-2 dientes-1 espina; ventrolateralmente destacan una espina y un tubérculo apicales; tarso con 2 espinas a cada lado; dorso del pedipalpo con gránulos dispersos. Color pardo. Quelíceros. Joroba del artejo proximal irregularmente granulada, resto del quelícero liso. Color amarillo pálido. Patas. Muy robustas, especialmente las patas III y
IV, que tienen el fémur ligeramente curvado. Toda la superficie es suavemente granulosa. Trocánter amarillo pálido, resto pardo, con el extremo de los artejos más oscuro. Metatarso III notablemente engrosado, constituyendo un carácter sexual secundario masculino. Fórmula tarsal: 6, 10-12 (3), 7, 7.

Pene (Fig. 15D-E). Tronco del pene muy largo y estilizado, muy estrecho en la base y lentamente ensanchado hasta el extremo apical. Cuello nítido. Cabeza penial vagamente cuadrangular alargada, con cinco pares de fuertes sedas ganchudas en los ángulos inferiores, y dos pares de muy pequeñas sedas en la zona superior, uno frontal y otro en los ángulos anteriores. Glande voluminoso, acabando en una pieza linguiforme con un botón terminal.

Hembra (Fig. 5B). Similar al macho, aunque de mayor tamaño y con metatarso III no engrosado.

Comentarios: Según la clave propuesta, R. fuscus es la especie más parecida, siendo además la única cuya área de distribución abarca Río Muni, al haber sido citada de Camerún y Gabón. No se ha publicado ni una sola figura de dicha especie y la única descripción es la original, sintetizada por Roewer (1923). Según ésta, $R$. fuscus se diferenciaría de $R$. funilignorum por presentar sólo 6 artejos en el tarso III, por las áreas I y IV lisas (sin el par de tubérculos y la fila de gránulos, respectivamente), por el desarrollo de la armadura del terguito libre III (con un par de gruesas espinas) y por la coloración, amarillo-tostado uniforme, muy diferente del contrastante diseño de $R$. funilignorum, con una gruesa línea negra rodeando el escudo y con líneas claras (sin pigmentación oscura) en el interior y entre las áreas del escudo. El pene de R. fuscus, descrito por Bauer \& Prieto (2009), es similar al de R. funilignorum.

Por su parte, Lawrence (1957) diferencia $R$. fuscus de $R$. robustus con los mismos caracteres (coloración amarillo-rojiza, tarso III con 6 artejos) que los utilizados aquí para separarla de $R$. funilignorum. Según la descripción, $R$. robustus presenta el fémur del pedipalpo más grueso y más fuertemente dentado, coxas IV 
con sendas filas de gránulos a lo largo de los bordes laterales, patas más cortas y fuertes, borde del escudo provisto de hileras de gránulos y armadura del terguito libre III más desarrollada.

Bauer \& Prieto (2009) también describen $R$. puylaerti, una nueva especie de Camerún que se diferencia de $R$. funilignorum por un diferente contorno corporal, un escudo dorsal desarmado, un espolón en el lado interno de la coxa IV, una coloración pardo-amarillenta y especialmente la morfología penial, con un tronco del pene engrosado y una cabeza penial con forma pentagonal.

Rhabdopygus benoiti es la única especie de la que se ha publicado una ilustración del pene (Kauri 1985) y las diferencias con $R$. fuscus y las nuevas especies (R. puylaerti y $R$. funilignorum) son conspicuas: la cabeza penial es ovalada y carece de sedas en su parte basal, y el borde frontal presenta un saliente troncocónico con sedas a ambos lados; evidentemente, " $R$. benoiti" tampoco forma parte del taxón Rhabdopygus.

\section{Subfamilia SELENCINAE Roewer 1935}

Taxón compuesto por 17 géneros, monotípicos en su mayoría, extendido exclusivamente por África occidental y el Golfo de Guinea (Roewer 1912, 1923, 1927, 1935, Sørensen 1896): Bolama Roewer 1927 y Cassinia Roewer 1927 en Guinea-Bissau; Seuthes Roewer 1935 en Sierra Leona; Umbonimba Roewer 1953, Sassandria Roewer 1912 (con otra especie en Ghana) y Seuthesplus Roewer 1935 (con otra en Nigeria) en Costa de Marfil; Selenca Sørensen, 1896 (y además en Togo), Binderia Roewer 1935, Jaundea Roewer 1935, Metaselenca Roewer 1912, Euselenca Roewer 1923 (con otra especie en Congo) en Camerún; Izea Roewer 1927 en la isla de São Tomé (con otra en Camerún); Selencasta Roewer 1935 y Selencula Roewer 1935, en la isla de Bioko; Seuthessus Kauri, 1985 en la R.D. del Congo; Humbea Roewer, 1935 en Angola y, con mención aparte, Paraselenca Roewer, desde Costa de Marfil hasta Camerún.
Según Starȩga (1992), la cuarta especie del género Paraselenca sería $P$. simonis Henriksen 1932, de Sierra Leona, pasando por alto que Roewer (1935) la había emplazado en el género Seuthes. La sinonimización (implícita) no parece suficientemente justificada puesto que ambos géneros pueden separarse por tres caracteres de posible rango genérico (área I entera, terguito libre III desarmado, fémur del palpo con espina mesoapical, en Seuthes). Por contra, las diferencias entre Seuthes y Seuthessus parecen limitadas a la armadura del tercer terguito libre, y la gran distancia geográfica entre ambos (casi $4000 \mathrm{~km}$ ) sería el mayor argumento en contra de la sinonimización.

El emplazamiento genérico de las tres especies encontradas de esta subfamilia es claro, según la siguiente clave inspirada en la de Roewer (1935) con la incorporación de los géneros descritos posteriormente y la eliminación de los sinonimizados por Starȩga (1992). Sin embargo, los caracteres diagnósticos de género parecen banales y la valoración de las diferencias peniales no es posible puesto que sólo se ha publicado la morfología penial de una especie (Kauri 1985) por lo que no cabe duda de que el conocimiento de la morfología penial de las especies típicas de los géneros de este grupo llevará a una profunda reorganización del mismo.

\section{Clave simplificada para la subfamilia Selencinae:}

1. Distitarso II con 3 artejos . ..............

-. Distitarso II con 4 o más artejos. ............. ... . . . . . . . . . . Casinia, Humbea y Sassandria

2. Área I entera . . . . . . . . . . . . . . . . 3

-. Área I dividida por un surco medio . . . . . . . . . . . . $\ldots \ldots \ldots \ldots \ldots$ Selenca y géneros afines

3. Tarso I con 5 artejos . . . . . . . . . . . . . . 4

Tarso I con 6 o más artejos. . . . . . . . . . . . .7

4. Área IV desarmada ...................5

Área IV con un par de espinas ..............

................. Umbonimba y Bolama

5. Área $\mathrm{V}$ con un par de espinas. . . . . . . . . . . . . 6

Área V desarmada. ............ Seuthesplus

6. Tercer terguito libre desarmado ......... Seuthes

Tercer terguito libre armado con una fila de espinas

..................... Seuthessus

7. Cuerno frontal delante del oculario; áreas I-V y 
terguitos libres con espinas. . . . . . . . . . . 8

-. $\quad$ Sin cuerno frontal; áreas I-V y terguitos libres

completamente desarmados ......... Metaselenca

8. Área IV desarmada; fémur del palpo con una espina mesoapical. ................. Binderia

-. Área IV con un par de espinas; fémur del palpo con

2 espinas mesoapicales.............. Izea

\section{Género Seuthessus Kauri 1985}

\section{Especie típica: Seuthessus pustulatus Kauri 1985}

Diagnosis: Tubérculo ocular con un par de pequeños tubérculos; área I del escudo no dividida por un surco medio; áreas I-III y V con pares de tubérculos; área IV desarmada; terguitos libres I-III con sendas filas transversales de 4-5 tubérculos; fémur del pedipalpo con una espina mesoapical; fórmula tarsal: $5,>6,>6$, $>6$; distitarso II con tres artejos (Kauri 1985).

\section{English diagnosis of new taxon}

Seuthessus coriscanus sp. nov. (Holotype: MNCN, Madrid; type locality, Corisco Island, Equatorial Guinea) Figs. 6, 16. Measurements in table 3.

Dark brown, with darker reticulation on lateral edges, areas of the scutum, free tergites and sternites; coxae rust brown, trochanters lighter, femora and following segments reticulated in black. Relative length of frontal processes, 26362; frontal area slightly produced and armed with a granule; ocularium with a pair of small tubercles. Scutum without a median groove on area I; areas I-II with paramedial pairs of spines, area III and V with pairs of stronger spines; free tergites with a row of small spines on each, where the paramedian pair and the marginal pair are stronger. Spiracles concealed by 4-5 sternal protuberances, bridging to the coxae IV. Anal operculum with two rows with four protuberances. Palp femur with +15 close denticles on ventral side and an mesoapical spine; tibia with two ventroapical facing spines and another on the ventromesal edge; tarsus with two spines on each side. Chelicera with dorsal granules. Legs with small granules, a conspicuous calcaneus on metatarsi III and IV; tarsal formula: 5, 10 (3), 6, 7. Penis spoon-shaped, penis head dorsally concave and provided with three pairs of setae on the ventral side, two foliate setae on each lateral side, three pairs of setae on the dorsal side (the basal pair on individual bumps overhanging the excavation and the apical one flanking a frontal notch). Glans with long fringed Stacheltrichter.

Seuthessus coriscanus sp. nov.

(Figs. 6, 16)

\section{Localidad típica: Corisco: Punta Koto.}

Holotipo: $\sigma^{7}$ (MNCN/20.02/17076, exZUPV/2079). Paratipos: $3 \sigma^{\top}+2 q$, ZUPV/2079, datos del holotipo; 1, ZUPV/2027, Corisco: Lago Aukati.

Etimología: De la localidad típica, Corisco, una pequeña isla de apenas $15 \mathrm{~km}^{2}$ que cierra la bahía de Corisco.

Diagnosis: Diferente de la especie típica por carecer de espina mesoapical en el fémur del pedipalpo y los pares de puntos redondos más claros en el escudo y presentar una cabeza penial con menor número de espinas y escotadura frontal menos profunda.

Descripción: Coloración (Fig. 6A). Pardo oscura, con reticulación oscura en los bordes laterales del carapacho y escudo, en las áreas del escudo y en los terguitos libres, esternitos oscuros. Coxas de color pardo orín, trocánteres algo más claros, resto de patas reticuladas en negro.

Cara dorsal (Fig. 16A-B). Carapacho progresivamente ensanchado hacia el opistosoma, el cual se abomba en el dominio de las áreas II y III, y luego toma bordes paralelos. Longitud relativa de los procesos frontales, 26362. Área frontal ligeramente protuberante y provista de un gránulo. Tubérculo ocular ovalado con un par de gránulos junto a cada ojo. Superficie finamente granulada, con una fila de gránulos en el borde delantero del carapacho. Borde anterior del escudo ligeramente 

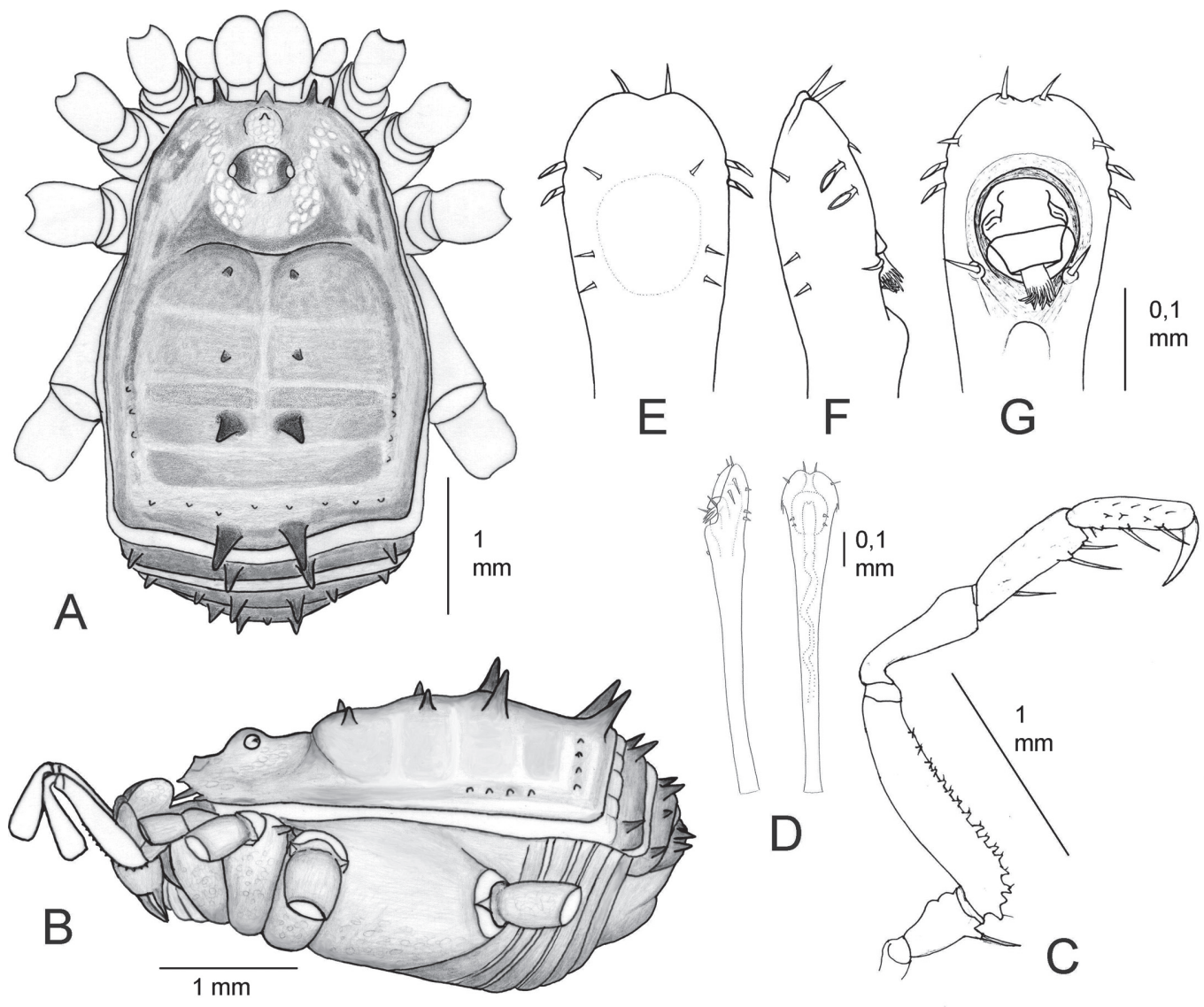

Fig. 16. Seuthessus coriscanus sp. nov. Holotipo ơ?. A, dorsal; B, lateral; C, pedipalpo derecho (ectal); D, pene; E-G, cabeza penial (ventral, lateral y dorsal).

Fig. 16. Seuthessus coriscanus sp. nov. Holotype $0^{\top}$. A, dorsal; B, lateral; C, right palp (ectal); D, penis; E-G, penial head (ventral, lateral and dorsal).

escotado, sugiriendo una leve depresión media. Áreas I y II con sendos pares centrales de tubérculos espinosos; áreas III y V con un par central de grandes espinas; área IV desarmada. Terguitos libres I-III granulados provistos de un par mediano de espinas, otro de espinas marginales y algunas espinas intercaladas de menor desarrollo. Cara ventral. Coxa I con la hilera posterior formada por gránulos pequeños irregularmente dispuestos en una doble hilera, hilera central con unos ocho gránulos pequeños salvo los dos apicales, hilera anterior con
5-6 protuberancias digitiformes apretadamente dispuestas; resto de las coxas dispersamente granulosas. Espiráculos protegidos por 4-5 protuberancias esternales gruesas, tres haciendo puente hasta la coxa. Esternitos con hileras de gránulos. Opérculo anal con dos hileras de cuatro granos romos.

Pedipalpos (Fig. 16C). Trocánter con una espina ventral; fémur con aspecto aserrado por la presencia de una fila 15 o más dentículos pequeños y regulares. Tibia con dos espinas mesales, basal y subapical, y una 
ectal emparejada con la mesoapical. Tarso con dos espinas a cada lado. Quelíceros. Artejos proximal y medio con gránulos dorsales. Patas. Granuladas desde la coxa, en los metatarsos III y IV es muy evidente la diferencia entre astrágalo y calcáneo. Fórmula tarsal: 5, 10 (3), 6, 7.

Pene (Fig. 16D-G). Con forma de cuchara. Tronco ensanchándose progresivamente, especialmente en su tercio apical, finalizando bruscamente en un engrosamiento mediodorsal. Cabeza penial ensanchada, aplanada dorsoventralmente, cóncava en su lado dorsal y con una leve escotadura en su borde frontal. Cara ventral con tres pares de sedas formando dos líneas paralelas, dos en la parte basal y el tercero a media distancia del extremo apical. Borde lateral con dos sedas foliadas situadas en la parte más ancha. Cara dorsal con tres pares de sedas, las basales sobre sendos engrosamientos del borde lateral inferior de la concavidad, las medias junto al borde lateral superior y por encima de la concavidad y las superiores, tan grandes como las basales, sobre pequeñas protuberancias flanqueando la escotadura apical. Glande ancho, tubular y plegado en la concavidad dorsal, con "Stacheltrichter" formado por largos flecos.

Hembra (Fig. 6B). Similar al macho salvo por el menor abombamiento lateral del escudo.

Comentarios: Seuthessus pustulatus es la única especie de Selencinae de la que se conoce la morfología penial (Kauri 1985). Se diferencia de la especie aquí descrita por: un par adicional de procesos frontales flanqueando el central y los marginales más largos que el central; sin protuberancia con gránulo en el área frontal; pedipalpo con fémur más corto y robusto, e hilera ventral con diez dientes; áreas del escudo con pares de máculas claras flanqueando las protuberancias centrales; pene con perfil diferente, con mayor número de espinas y una profunda escotadura frontal.

\section{Género Seuthes Roewer 1935}

Especie típica: Paraselenca simonis Henriksen 1932
Diagnosis: Tubérculo ocular con un par de espinitas; área I del escudo sin surco longitudinal medio; áreas I-III y V con pares de espinas; área IV desarmada; terguitos libres I-II con sendas filas de cuatro espinas; terguito libre III desarmado; fémur del pedipalpo con una espina mesoapical; fórmula tarsal: $5,>6,6,>6$; distitarso II con tres artejos (Roewer 1935).

\section{English diagnosis of new taxon}

Seuthes inermis sp. nov. (Holotype: MNCN, Madrid; type locality, Congüe River, Equatorial Guinea) Figs. 7, 17. Measurements in table 3.

Orange yellow upper surface, finely reticulated in dark, with irregularly distributed white dots. Pale yellow chelicera and trochanters, brown remainder parts of legs. Carapace with a lateral edge angled on coxa II and a granule row on the frontal edge; relative length of frontal processes, 36463; ocularium with granules and a tubercle pair. Scutum without a median groove on area I; areas I-II with a pair of paramedian small spines; area III with a median pair of strong spines flanked by a pair of half sized spines; area IV unarmed; area V with two spines somewhat longer than the spines of area III. Free tergites with a row of whitish granules on each. Coxae IV with some whitish granules. Spiracles concealed by 4-5 sternal, some bifurcate, and 2-3 coxal protuberances. Palp femur with many decreasing denticles on ventral side and a mesoapical spine; tibia with two ventroapical facing spines and another on the ventromesal edge; tarsus with two spines on each side. Chelicera with globose and granulate bulla. Long legs, white granulated trochanters, brown femora with whitish granules and a dorsal row of yellowish spots; a conspicuous calcaneus on metatarsi III and IV; tarsal formula: 5/4, 12/11 (3), 6, 7. Penis spoon-shaped with conspicuous frontal notch, penis head heartshaped with three pairs of setae on the ventral side, two foliate setae on each lateral side, three pairs of setae on the dorsal side (the basal pair on the rim of the excavation and the apical one flanking the frontal notch). 

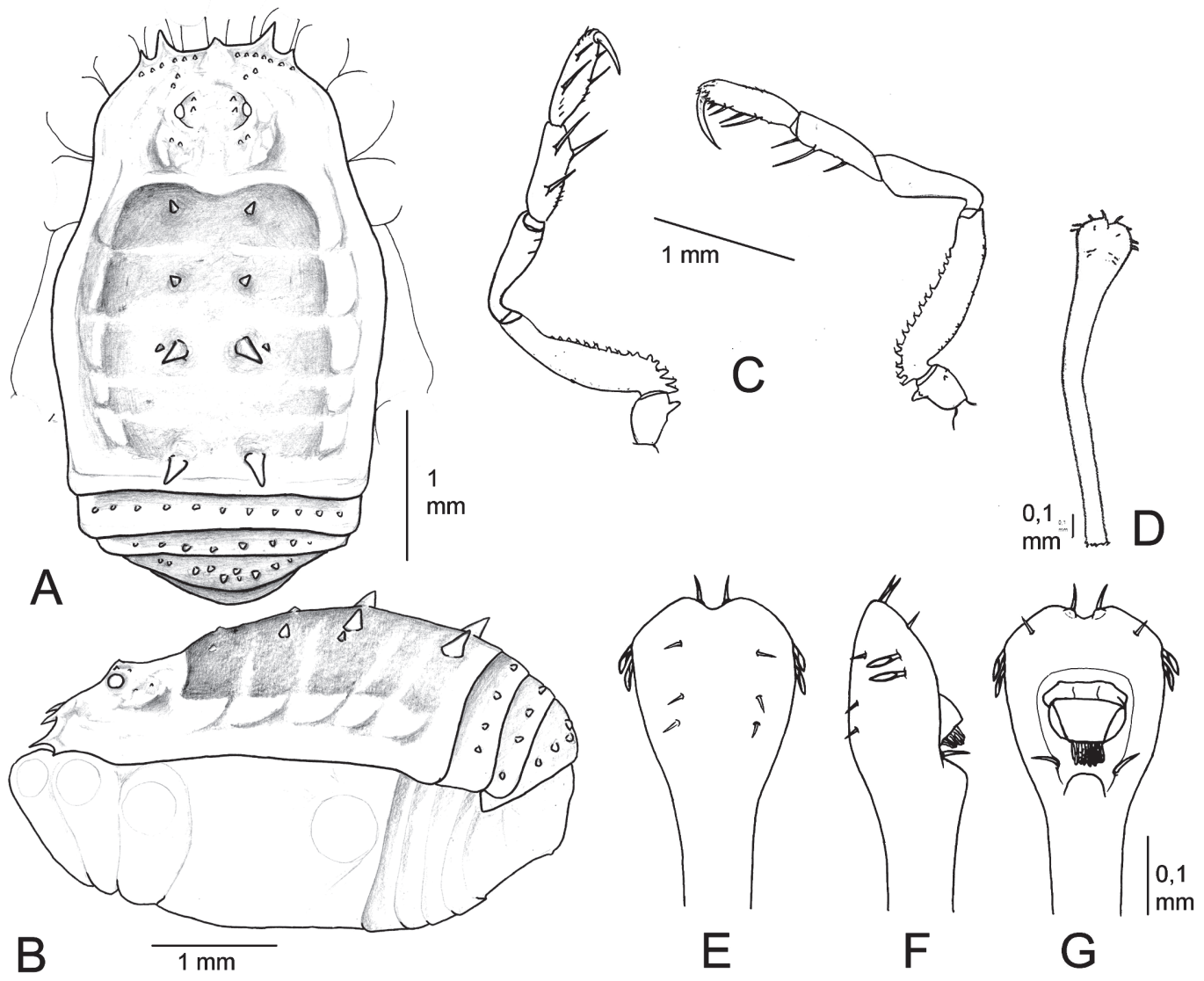

Fig. 17. Seuthes inermis sp. nov. Holotipo Oౌ. A, dorsal; B, lateral; C, pedipalpo izquierdo (mesal y ectal); D, pene; E-G, cabeza penial (ventral, lateral y dorsal).

Fig. 17. Seuthes inermis sp. nov. Holotype $\sigma^{\top}$. A, dorsal; B, lateral; C, left palp (mesal and ectal); D, penis; E-G, penial head (ventral, lateral and dorsal).

Seuthes inermis sp. nov.

(Figs. 7, 17)

Localidad típica: Río Congüe: bosque primario de elondo.

Holotipo: $\sigma^{\top}(\mathrm{MNCN} / 20.02 / 17077$, exZUPV/2007). Paratipos: $10^{\top}+19$, ZUPV/2007, datos del holotipo. 1', ZUPV/2035, Río Motora (Mitong): $3 \mathrm{~km}$ al Este del puente. 1 , ZUPV/2046, en Río Motora (Mitong): $1 \mathrm{~km}$ al Este del puente. 10 $0^{\top}$, MNCN-20-02/11939, Río Benito (=Mbini), F. Bonet y J. Gil leg. 1 Q, MRAC/170078, Entre Mbane y Abenelang, $0^{\circ} 49^{\prime} \mathrm{N} 9^{\circ} 23^{\prime} \mathrm{E}, \mathrm{M}$. Alderweireldt leg. [Las coordenadas son del islote Mbañe (de $0.5 \mathrm{~km}$ de longitud y a $20 \mathrm{~km}$ de la costa), pero en tierra firme existen dos localidades llamadas Mbañe y Abebelang dentro de la misma cuadrícula UTM 32NPG01, que es la representada]

Etimología: Aludiendo a la ausencia de armadura en los terguitos libres, un conspicuo carácter diagnóstico.

Diagnosis: Especie identificable por la presencia de cuatro espinas en el área III, terguitos libres desarmados, gránulos con punta 
blanca de terguitos, y fémur del pedipalpo sin espina mesoapical.

Descripción: Coloración (Fig. 7A). Cara dorsal amarilla anaranjada, finamente reticulada en oscuro, con puntos blancos más o menos irregularmente dispuestos. Quelíceros y trocánter de todas las extremidades amarillo pálido, resto de las extremidades pardas. Cara ventral totalmente anaranjada.

Cara dorsal (Fig. 17A-B). Carapacho con angulosidad lateral sobre la coxa II, y luego progresivamente ensanchado hacia el opistosoma, cuyos bordes laterales se ensanchan en el dominio de las áreas I-III, y después se hacen paralelos. Longitud relativa de los procesos frontales, 36463. Parte delantera del carapacho con una fila de gránulos. Tubérculo ocular ovalado, con un par de gránulos más grandes junto a los ojos, y con pequeños gránulos dispersos. Borde anterior del escudo ligeramente escotado, esbozando una leve depresión media del área I. Áreas I-II con un par de pequeñas espinas centrales; área III con un par central de espinas, el doble de largas que el par de espinas más lateral; área IV desarmada, con dos pequeños gránulos centrales; área $\mathrm{V}$ con un par de espinas vez y media más largas que las centrales del área III. Superficie del escudo dorsal orlada por pequeños gránulos blancos dispersos. Terguitos libres I-III con sendas filas transversales de pequeños gránulos blancos. Coxas IV con numerosos gránulos blancos.

Cara ventral. Coxa I con la hilera posterior formada por inconspicuos gránulos, hilera central con bajas y aisladas protuberancias primero y luego progresivamente más grandes y juntas, hilera anterior con 5-6 protuberancias digitiformes; resto de las coxas dispersamente granulosas. Espiráculos traqueales protegidos por 4-5 protuberancias esternales gruesas, a veces con su extremo ensanchado o bifurcado, y 2-3 pequeñas protuberancias coxales. Esternitos con hileras de gránulos. Opérculo anal granuloso.

Pedipalpos (Fig. 17C). Trocánter con una espina ventral. Fémur ventralmente dentado. Patela alargada. Tibia con una espina ventromesal y otra ventrolateral en su zona apical, y con una espina ventromesal en su zona basal. Tarso con dos espinas a cada lado. Quelíceros. Artejo proximal con joroba fuertemente hinchada y muy finamente granulada; artejo medio con sedas dispersos. Patas. Largas y delgadas. Trocánteres con gránulos blancos; fémures de color pardo, con algunos gránulos blancos y una hilera dorsal de máculas amarillas. Metatarsos III y IV con astrágalo y calcáneo muy marcados. Fórmula tarsal: (I/D) 5/4, 12/11 (3), 6, 7.

Pene (Fig. 17D-G). Con forma de cuchara, $1=1.35 \mathrm{~mm}$. Tronco de grosor uniforme hasta el cuello, donde presenta un engrosamiento dorsal que finaliza bruscamente. Cabeza del pene acorazonada, excavada dorsalmente y provista de una ligera escotadura frontal. Cara ventral con tres pares de sedas formando dos líneas paralelas, dos basales y el tercero algo más alejado. Borde lateral con dos fuertes sedas foliadas en la parte más ancha. Cara dorsal con tres pares de sedas, uno flanqueando el glande sobre engrosamientos del borde de la concavidad, otro junto al borde laterofrontal y el tercero sobre sendas protuberancias flanqueando la escotadura frontal.

Hembra (Fig. 7B). Similar al macho salvo por el menor abombamiento lateral del escudo.

Comentarios: $S$. simonis se diferencia de la especie aquí descrita por: terguitos libres I y II con sendas filas de cuatro espinas; terguito libre III con dos filas de gránulos; filas de dentículos bordeando los laterales del escudo; superficie dorsolateral de las coxas IV con tres gruesas protuberancias. Dada la ausencia de figuras en la descripción original, basada además en una hembra, no ha sido factible establecer diferencias más conspicuas. Hasta que no se conozca el macho de $S$. simonis no se podrá verificar si el emplazamiento genérico, fundamentado exclusivamente en los caracteres reseñados en la clave, es correcto ya que en la diagnosis del género se alude a la armadura de los terguitos libres I y II. 


\section{Género Binderia Roewer 1935}

Especie típica: Binderia spinarmata Roewer 1935

Diagnosis: Tubérculo ocular con un par de espinitas; área I del escudo sin surco longitudinal medio; áreas I-III con pares de espinas, área IV desarmada, área $\mathrm{V}$ y terguitos libres I-III con filas de espinas; tarso I con 6 artejos, el resto con más de 6; distitarso II con tres artejos (Roewer 1935).

Comentarios: La única especie de este género se conoce solamente de la localidad típica, Binder (norte de Camerún), la cuál no ha sido encontrada en la cartografía; podría ser un error de transcripción de 'Guider' $\left(9^{\circ} 55^{\prime} \mathrm{N}\right.$, $\left.14^{\circ} 5^{\prime} \mathrm{E}\right)$.

\section{English diagnosis of new taxon}

Binderia longipes sp. nov. (Holotype: MNCN, Madrid; type locality, Monte Alén National Park, Equatorial Guinea) Figs. 8, 18. Measurements in table 3.

Light brown upper surface, with darker zones on the carapace, the periphery of the scutum and around the scutal spines; area V and free tergite I with central dark zone; free tergites II-III with wider dark zone. Yellowish ventral surface with dark esternites. Carapace with a small tubercle in front of the ocularium, which has two pairs of granules, and two separated spines behind the ocularium; relative length of frontal processes, 26362. Scutum with granule lateral rows; areas I-III and V with a paramedian pair of spines on each, stronger on areas III and V; area IV with a pair of wide separated granules and area $\mathrm{V}$ with additional pairs of lateral and marginal spines; free tergites with a spine row on each; coxae IV with 2-3 denticles. Spiracles concealed by 5-6 slender cuticular bridges. Anal operculum with three granule rows. Palp femur ventrally toothed, tibia with two ventroapical facing spines and another on the ventromesal edge; tarsus with two spines on each side. Chelicera with globose and granular bulla. Long and brownish legs, but trochanters and tarsi III-IV are yellowish; tarsal formula: 7/6, 15/14 (3), 7, 9. Penis bladeshaped; penis head straight sided with a frontal notch, three pairs of setae on ventral side, two foliate setae on each lateral side, three pairs of setae on the dorsal side (all above the glans). Glans bell-shaped, with two lobes embracing a filiform bunch.

Binderia longipes sp. nov.

(Figs. 8, 18)

Localidad típica: Parque Nacional de Monte Alén, Ayene, cabecera río.

Holotipo: $\sigma^{\top} \quad(\mathrm{MNCN} / 20.02 / 17078$, ex-ZUPV/2039).

Etimología: Alude a la notable longitud y delgadez de las patas.

Diagnosis: Cuerpo pequeño y patas largas (PII/C=8), con 14-15 artejos en el tarso II y 9 en el IV; carapacho sin filas de gránulos en el borde anterior y en los laterales.

Descripción: Coloración (Fig. 8A). Cara dorsal amarillenta, con la zona central del carapacho y de las áreas I-IV pardo oscura; área V y terguito libre I oscuros en su parte central, terguitos libres II y III oscuros en toda su anchura. Cara ventral parda amarillenta, esternitos oscuros. Pedipalpos de color pardo.

Cara dorsal (Fig. 18A-B). Tubérculo ocular pequeño y ovalado, centrado en el carapacho, con un par de gránulos junto a cada ojo. Longitud relativa de los procesos frontales, 26362. Borde delantero del carapacho con una fila de gránulos y un pequeño gránulo en la posición del cuerno prosómico. Áreas I-III y área V del escudo cada una con un par central de espinas, especialmente robustas en las áreas III y V; área $\mathrm{V}$ también con pequeñas espinas laterales y marginales; área IV desarmada con un par de gránulos bien separados entre sí. Borde lateral del escudo con gránulos dispersos. Terguitos libres I-III con filas de espinas. Coxas IV dorsalmente con 2-3 pequeños dientes. 


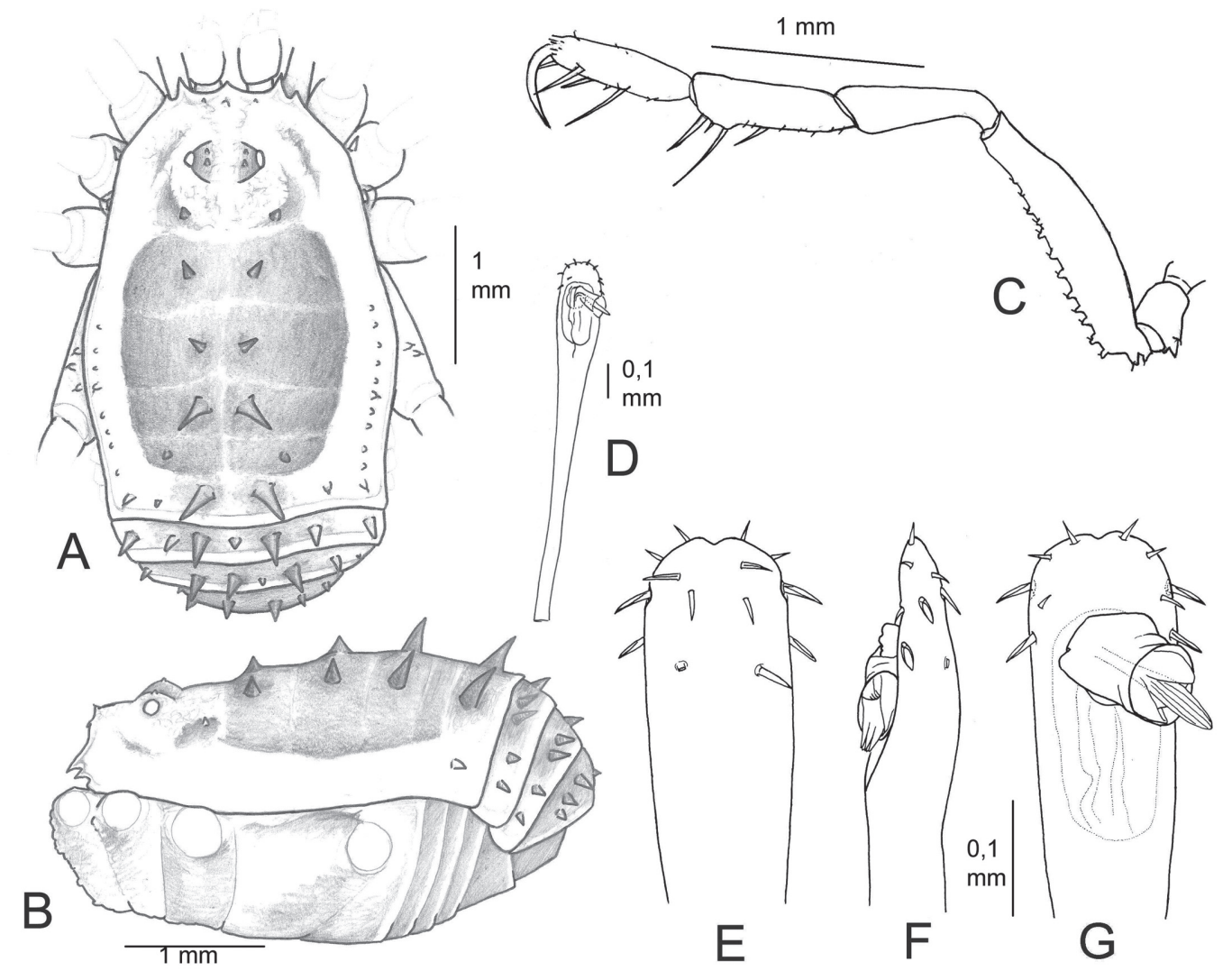

Fig. 18. Binderia longipes sp. nov. Holotipo ${ }^{\top}$. A, dorsal; B, lateral; C, pedipalpo izquierdo (ectal); D, pene; E-G, cabeza penial (ventral, lateral y dorsal).

Fig. 18. Binderia longipes sp. nov. Holotype $\mathrm{O}^{\top}$. A, dorsal; B, lateral; C, left palp (ectal); D, penis; E-G, penial head (ventral, lateral and dorsal).

Cara ventral. Coxas I con tres filas de tubérculos, la anterior formada por cinco tubérculos regulares, la central con 7 a 9 tubérculos más grandes y próximos entre sí en el extremos de la coxa, y la tercera fila apenas visible; resto de las coxas granulosas. Espiráculos protegidos por 5-6 estrechos puentes cuticulares. Esternitos con sendas filas de gránulos; opérculo anal con tres filas de gránulos.

Pedipalpos (Fig. 18C). Trocánter con un par de pequeños dientes ventrales; fémur ventralmente dentado; patela alargada; tibia con dos largas espinas ventromesales, y con una larga espina apicolateral; tarso con dos espinas a cada lado. Quelíceros. Artejo proximal liso, medio con algunas sedas dispersas. Color pardo amarillento.

Patas. Muy alargadas y finas, de color pardo uniforme salvo trocánteres y tarsos III y $\mathrm{IV}$, que son amarillentos. Fórmula tarsal (I/D): 7/6, 15/14 (3), 7, 9.

Pene (Fig. 18D-G). Con forma de pala. Tronco del pene uniformemente delgado hasta el tercio distal, donde engrosa regularmente y continúa en la cabeza penial sin solución de continuidad. Cabeza penial con lados paralelos, con escotadura frontal apenas esbozada y concavidad del glande ampliamente separada 
del borde frontal. Cara ventral provista de tres pares de sedas, el basal más alejado y con sedas más separadas que los otros dos pares. Borde lateral con tres pares de sedas, el basal con grandes sedas foliáceas, el intermedio junto a la curvatura latero-frontal y el apical flanqueando la escotadura. Cara dorsal provista de dos pares de sedas, el basal con grandes sedas foliáceas flanqueando el glande. Glande campaniforme, con su interior ocupado por dos lóbulos que rodean un grupo compacto de procesos filiformes que protegen el estilo.

Comentarios: La otra especie del género, B. spinarmata se diferencia por poseer filas de gránulos en el borde delantero y en los lados del carapacho, y por carecer de un par de gránulos tras el tubérculo ocular; además, sólo 10-11 artejos en el tarso II y 8 en el tarso IV, y patas notablemente más cortas (pata II cinco veces la longitud del cuerpo, frente a ocho veces en Binderia longipes).

\section{Subfamilia POLYCORYPHINAE Roewer 1935}

Comprende 33 géneros, mayoritariamente monotípicos, y su área de distribución incluye la Región Etiópica, excepto África occidental, y la Región Oriental (desde India a Indochina). En África, la subfamilia está representada por 13 géneros (Goodnight \& Goodnight 1944, Kauri 1985, Roewer 1912, 1927, 1935, 1950): Maracandinus Roewer 1912 y Gulufia Roewer 1935 de Etiopía; Procoryphus Roewer 1950, Pulchandrus Kauri 1985 y Uviranus Kauri 1985 de la región oriental de la R. D. del Congo; Parakodaika Goodnight \& Goodnight 1944 y Polycoryphus Loman 1902 de Namibia/ Angola; Thomecola Roewer 1927, Santhomea Roewer 1927, Palmanella Roewer 1927 y Henriquea Roewer 1927 de las islas de São Tomé y Príncipe; y finalmente, Binderella Roewer 1935 y Bueana Roewer 1927 de Camerún.

En el material estudiado se han identificado tres especies concordantes con la diagnosis de la subfamilia pero ninguna de ellas relacionable con alguno de los géneros descritos. Una de ella fue tratada como perteneciente a los Erecinae durante el proceso de estudio, ya que la ausencia de cuerno frontal es propia de dicha subfamilia y nuestra especie lo presentaba muy reducido. Sin embargo, la estructura del pene de Ayenea es muy diferente de la descrita por Kauri (1985) para numerosos erecinos, pero similar a la que presentan las otras dos especies, lo que nos hizo reconsiderar su emplazamiento. Debido a la peculiar conformación del pene de estas especies, se considera necesario describirlo de forma general para todas ellas, precisando los detalles particulares en la descripción de cada taxón.

\section{Estructura del pene de los Polycoryphi-} nae de Río Muni: El tronco del pene está dividido en dos partes de similar longitud; la parte basal es corta y gruesa, hialina, mientras que la distal está dilatada, con gruesas paredes vítreas de color amarillo, y finaliza en dos lóbulos separados por una escotadura. El glande se asienta en el lado dorsal de la escotadura, es cilíndrico y de longitud variable, dejando ver en su interior un cilindro espinoso rodeando el estilo. Los lóbulos laterales presentan varios pares de sedas, las cuales parecen estar conectadas mediante raíces con una matriz interna, casi opaca y común a todas ellas. Esta matriz se extiende bajo la gruesa pared vítrea por ambos lados de la cavidad central que aloja al glande hasta converger en la base de la zona dilatada. En la superficie de la cara dorsal se aprecia una depresión o hendidura donde desembocan dos conductos que evacuarían la secreción que produciría la matriz interna. El conducto evacuador se forma tras la confluencia de varias hebras surgidas de la cara dorsal matriz interna.

El único dato publicado sobre la morfología del pene de los Polycoryphinae africanos se debe a Kauri (1985), quien ilustra esquemáticamente la región apical de Pulchandrus longimanus Kauri 1985, con la que no encontramos ninguna similitud. Suzuki (1985) describe e ilustra el pene de dos nuevos policorifinos tailandeses, Maracandellus bidentatus Suzuki 1985 y Paramaracandus sexdentatus Suzuki 
1985, con los que tampoco apreciamos relación morfológica alguna.

\section{Clave abreviada de los géneros africanos:}

1. Todas las áreas del escudo y los terguitos libres desarmados ...........................

-. Algún área del escudo o terguito libre con espinas o

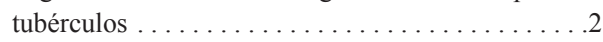

2. Todos los terguitos libres con filas de espinas o tubérculos ............Santhomea, Thomecola, Palmanella, Henriquea Gulufia, Parakodaika, Procoryphus, Uviranus y Pulchandrus,

-. Ninguno de los terguitos libres con más de tres espinas/tubérculos. . . . . . . . . . . . . . 3

3. Todas las áreas del escudo y los terguitos libres con un par de tubérculos .............Polycoryphus

-. Áreas I-III con dos espinas y área IV desarmada. . .4

4. Fórmula tarsal: $6,+10,7,+8 \ldots$ Bueana y Binderella

-. Fórmula tarsal: $5,+10,6,7 \ldots \ldots \ldots \ldots \ldots$

5. Áreas I-III y terguito libre III con pequeños tubérculos . . . . ...................

-. Áreas I-III y terguito libre III con largas espinas. . .6

6. Área $\mathrm{V}$ y terguito libre I desarmados . . . . . . . . . . . Área V y terguito libre I armados con una o dos espinas....................... Niefanga

\section{English diagnosis of new taxon}

Ayenea gen. nov. (Type species, Ayenea trimaculata sp. nov.)

Member of the subfamily Polycoryphinae with the frontal horn reduced to a small tubercle and ocularium with two pairs of grains. Scutum areas I-III with paramedian pair of tubercles on each, areas IV-V and free tergites unarmed; scutum with white patches in interareas I-IV. Spiracles concealed by 2-3 long processes. Tarsal formula: 5, 15 (3-4), 6-7, 7-8. Penis short and robust penis, with a bilobed and swollen distal part, lobes provided with four setae; secretion collector tubes leading into a median split; glans penis stands out above the lobes.

\section{Género Ayenea nov.}

Especie típica: Ayenea trimaculata sp. nov.

Etimología: De Ayene, población del Parque Nacional de Monte Alén cercana al lugar de recogida de estos opiliones. Género gramatical, femenino.

Diagnosis: Cuerno frontal reducido a un pequeño tubérculo, tubérculo ocular con dos pares de gránulos. Áreas I-III con pares de tubérculos, áreas IV-V y terguitos libres desarmados. Escudo dorsal con tres manchas blancas en las interáreas I-IV. Espiráculos cubiertos por 2-3 procesos quitinosos. Fórmula tarsal: 5 , 15 (3-4), 6-7, 7-8. Pene corto y robusto, con la parte distal hinchada y bilobulada, lóbulos provistos de cuatro sedas, colectores desembocando en una hendidura central, glande sobrepasando los lóbulos.

Comentarios: Esta especie, como sugiere la similar morfología del pene, pertenece al mismo grupo que Montalenia. Sus armaduras dorsales, a excepción del tamaño de las espinas (mucho mayores en Montalenia) son también muy similares, así como el notable dimorfismo sexual en el tamaño y longitud del cuerpo. Posiblemente Ayenea, Montalenia y Niefanga forman un grupo diferenciado dentro de Polycoryphinae.

\section{English diagnosis of new taxon}

Ayenea trimaculata sp. nov. (Holotype: MNCN, Madrid; type locality, Motora river, Equatorial Guinea) Figs. 9, 19. Measurements in table 3.

Pale yellow, with a broad median band and white spots on inter-areas I-II, II-III and III-IV; lateral and posterior scutum edges with a narrow dark stripe; free tergites and sternites with dark stripes; coxa IV and anal sclerites blackish, but rear edge of last sternite whitish. Body rectangular, without furrow between carapace and scutum. Carapace with a toothed frontal bump, an ocularium with two granule pairs and a lateral granule row continued on the scutum; relative length of frontal processes, 26362. Areas I-III without visible borders, with a paramedian pair of tubercles on each; areas IV-V unarmed; free tergites with transverse granule rows, where central granules are larger. 
Coxae I-III with dorsal facing tubercles, sometimes fused into a cuticular bridge. Coxae II-III separated by a broad sternum. Spiracles concealed by 3-4 sternal tubercles bent toward the coxa. Palp femur minutely serrated on ventral side; patella longer than tibia, which presents five spines (two longer) on ventromesal edge, one apical on ventrolateral edge and three dorsal granule row; tarsus with several spines on each edge and granular dorsal side. Dark chelicera with smooth bulla. Legs smooth and dark, tarsal formula: 5-6, 14-16 (3-4), 6-7, 7-9. Penis club-shaped with short stalk, glossy and deeply bilobed penis head, with three apical setae on each lobe; ventral and lateral sides with a pair of setae on each; secretion collector tubes leading into a median split; tubular glans penis stands out above the lobes. Female with elongated post-scutum abdomen, convex and whitish central part of coxosternal plate, genital operculum with a frontal notch.

Ayenea trimaculata sp. nov.

(Figs. 9, 19)

Localidad típica: Río Motora (Mitong): $1 \mathrm{~km}$ al E del puente.

Holotipo: o $\quad(\mathrm{MNCN} / 20.02 / 17079$, ex-ZUPV/2052). Paratipos: $4 \sigma^{\top}+7 \%$, ZUPV/2052bis. 20, ZUPV/2037, PNMA: Ayene, cabecera río. 1 Q, ZUPV/2025), PNMA: trayecto al Itinerario Pedagógico. $3 \sigma^{7}$ +1 ' , ZUPV/2033, Río Motora: $3 \mathrm{~km}$ al Este del puente. $1 \delta^{\top}+3 q, Z U P V / 2010$, P.N. de Monte Alén: Monte Alén, vertiente NW.

Etimología: Del latín, macula, mancha, por la presencia de tres manchitas blancas en las interáreas I-IV del escudo dorsal.

Descripción: Coloración (Fig. 9A). Amarillo pálido, con una franja longitudinal central oscura con tres manchas níveas en las interáreas I-IV. Bordes lateral y posterior del escudo con una línea de suave reticulación grisácea; terguitos libres amarillo pálido, con una línea transversal de reticulación oscura.
Ventralmente coxas I-III y esternitos amarillos con débil reticulado oscuro. Coxa IV muy oscura y opérculo anal negro salvo el borde posterior del último esternito.

Cara dorsal (Fig. 19A-B). Carapacho con un abultamiento frontal del que sobresale un pequeño diente. Tubérculo ocular ovalado, más próximo al borde delantero del carapacho que al posterior, con dos pares de pequeños gránulos. Longitud relativa de los procesos frontales, 26362 Borde lateral del carapacho y del escudo con una hilera de gránulos. Áreas I-III sin límites entre ellas, cada una con un par de tubérculos centrales, estando los del área I más separados que en las otras dos; el área III presenta una línea transversal más clara; áreas IV-V lisas; terguitos libres I-III con una fila transversal de pequeños gránulos muy débiles, siendo el central de los terguitos I-II y la pareja central del terguito III más prominentes. Cuerpo de forma vagamente rectangular. No existe surco entre carapacho y escudo dorsal, de tal manera que forman un escudo único. Coxas I a III con sendos pares de tubérculos, de los que destacan los contiguos de las coxas II y III, que se encuentran fusionados formando un puente cuticular.

Cara ventral. Coxa I con tres filas de gránulos, la primera muy corta, formada por cinco tubérculos y paralela a la central, formada por 8 tubérculos de mayor tamaño, especialmente los dos apicales; fila posterior con numerosos gránulos de pequeño tamaño. Resto de las coxas granulosas. Espiráculos protegidos por 3-4 largas prolongaciones cuticulares desde el esternito hacia la coxa. Coxas separadas por un esterno ancho. Esternitos libres con filas de gránulos. Opérculo genital de forma vagamente hexagonal.

Pedipalpos (Fig. 19C). Trocánter con una larga espina ventral; fémur dentado ventralmente, dándole un aspecto aserrado; patela muy alargada, de mayor longitud que la tibia; tibia ventromesalmente con cinco espinas (larga-2 cortas-larga-corta), y con una espina ventrolateral en la zona apical, y con tres filas de gránulos dorsales que le confieren un aspecto aserrado; tarso: destacan dos espinas a cada 

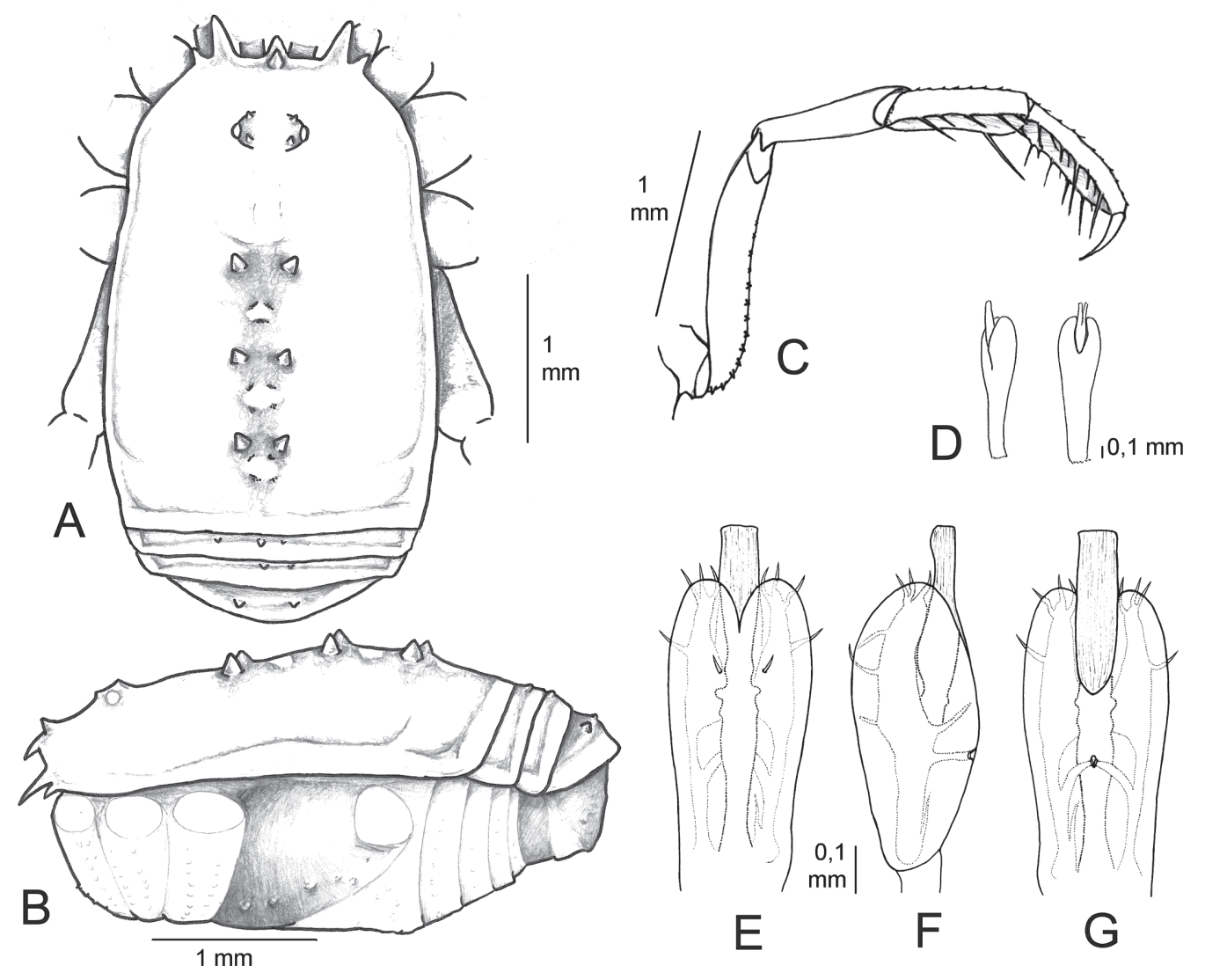

Fig. 19. Ayenea trimaculata gen. \& sp. nov. Holotipo o ${ }^{\top}$. A, dorsal; B, lateral; C, pedipalpo izquierdo (mesal); D, pene; E-G, cabeza penial (ventral, lateral y dorsal).

Fig. 19. Ayenea trimaculata gen. nov., sp. nov. Holotype §̋. A, dorsal; B, lateral; C, left palp (mesal); D, penis; E-G, penial head (ventral, lateral and dorsal).

lado. Todos los artejos con aspecto granuloso. Intensamente reticulados en negro. Quelíceros. Artejo proximal con joroba lisa, medio con algunas sedas dispersas. Negruzcos. Patas. Lisas, oscuras. Fórmula tarsal: 5-6, 14-16 (3-4), 6-7, 7-9.

Pene (Fig. 19D-G). Corto y claviforme. Longitud, $1.4 \mathrm{~mm}$. Tronco del pene corto, cilíndrico. Cabeza penial con aspecto vítreo, ovalada en vista lateral, hendida distalmente formando dos lóbulos apicales ovalados, cada uno de ellos con tres sedas apicales. Cara ventral con un par de sedas sobre el abombamiento ventral, con los lóbulos apicales separados por un surco profundo. Cara lateral con una seda en la zona más ancha. Cara dorsal carente de sedas. Colectores de la secreción penial desembocando lateralmente en la pared de una corta hendidura media. Glande cilíndrico, sobresaliendo frontalmente entre los dos lóbulos apicales. Cilindro espinoso largo, aplanado dorsoventralmente, con espinitas cortas.

Hembra (Fig. 9B-C). Semejante al macho, pero más grande y notablemente más larga debido a la gran distensión de la parte postescutal del abdomen. Coxas II y III separadas por un ancho esternón anaranjado profundamente encajado, dejando una ancha depresión. 
Opérculo genital transversalmente ovoidal, tanto en contorno como en volumen, con una hendidura frontal, pardo-anaranjada (amarillo pálido en machos). Esternito II notablemente abombado y de color amarillo pálido salvo una zona central reticulada en oscuro.

Comentarios: Todos los ejemplares estudiados presentan algún tipo de asimetría en el número de artejos de algunos tarsos. El tarso I es el más constante, con cinco artejos y 5-6 en los asimétricos. En el tarso II se han contado 13 y 17 en algunos asimétricos, con 14-16 artejos en la pata opuesta. El número de artejos del distitarso II, un carácter que Roewer (1935) utilizaba asiduamente, también varía entre tres y cuatro. Siguiendo la clave original de Roewer (1935), y asumiendo distitarso II = cuatro artejos, se llega al grupo guineano de Bueana y Binderella (asumiendo el otro valor, distitarso $\mathrm{II}=$ tres artejos, los pasos de la clave conducen hasta géneros de la India).

\section{English diagnosis of new taxon}

Niefanga gen. nov. (Type species, Niefanga spinosa sp. nov.)

Member of the subfamily Polycoryphinae with strong frontal horn and granular ocularium. Areas I-III with a paramedian pair of long spines on each, area IV unarmed, area $\mathrm{V}$ and free tergites I-II with a paramedian pair of long spines and a pair of short marginal spines in each, free tergite III with 3 spines. Spiracles concealed by four digitiform processes. Coxae II-III separated by a reddish broad sternum. Tarsal formula: 5, 11-12 (3), 6, 7. Penis fusiform, with a glossy central part provided with lateral setae, secretion collector tubes leading into a groove on the wall of the dorsal funnel. Female with non-elongated abdomen and without lengthened trident.

\section{Género Niefanga nov.}

Especie típica: Niefanga spinosa sp. nov.

Etimología: Niefang es la capital del distrito al que pertenece el Parque Nacional de Monte Alén. Género gramatical, femenino.
Diagnosis: Margen anterior del carapacho con un nítido cuerno frontal, tubérculo ocular granuloso. Áreas I-III con pares de espinas, área IV desarmada, área $\mathrm{V}$ y terguitos libres I-II con dos espinas medias y dos marginales, terguito libre II con dos espinas medias y dos marginales, y terguito libre III con tres espinas. Espiráculos traqueales cubiertos por cuatro tubérculos digitiformes curvados contra la coxa IV. Fórmula tarsal: 5, 11-12 (3), 6, 7. Pene fusiforme, con la parte vítrea provista de sedas laterales, colectores de las glándulas peniales desembocando en una fisura abierta en la pared superior de la depresión dorsal, y glande apical y tubular. Hembras con abdomen normal, sin especial desarrollo del tridente, y con coxas II y III separadas por un esternón de color rojizo.

\section{English diagnosis of new taxon}

Niefanga spinosa sp. nov. (Holotype: MNCN, Madrid; type locality, Monte Alén National Park, Equatorial Guinea). Figs. 10, 20. Measurements in table 3.

Pale yellow, including coxae and trochanters, excepting a postocular area reticulated in dark, a quadrangular patch occupying areas I-IV and the black spines. Carapace with a strong frontal horn, an ocularium with median groove and two granule pairs near eyes; relative length of frontal processes, 36263. Scutum areas I-III with a pair of long, strong spines, larger backward, on each; area IV unarmed; area $\mathrm{V}$ and free tergites I-II with a paramedian pair of long spines and a pair of smaller marginal spines on each; free tergite III with a median spine flanked by a pair of somewhat longer spines. Coxae I-II with two tubercles, dorsal and backward, with the rear of coxa II and a forward tubercle of coxa III fused into a cuticular bridge. Forward row of coxa I with three tubercles only; coxae II-IV with marginal tubercle rows and separated by a broad sternum. Spiracles concealed by 4 sternal tubercles bent toward the coxa; anal sclerites brownish. Palp femur with a small medioapical tooth and ventrally serrated in $2 / 3$ of its length; patella with a dorsal tooth; tibia with five ventromesal 
and two ventrolateral spines ( $1^{\text {st }}$ and $4^{\text {th }}$ longer); tarsus with four spines in each side. Basichelicerite with granular bulla. Legs long and slender, tarsal formula: 5, 11-12 (3), 6, 7. Penis with short stalk, long apical glans on a fusiform, vitreous penial head; with six setae on each lateral side, without setae on ventral and dorsal sides; secretion collector tubes leading into a groove opened on the wall of the dorsal funnel; tubular glans with a dorsal notch on the mouth, where a plumose Stacheltrichter lifts. Female larger, with a medial longer spine on the area $\mathrm{V}$, a broad triangular sternum with a notch and a genital operculum provided with a process directed towards the notch.
Niefanga spinosa sp. nov.

(Figs. 10, 20)

Localidad típica: Parque Nacional de Monte Alén: trayecto al Itinerario Pedagógico.

Holotipo: ơ, (MNCN/20.02/17080, exZUPV/2021). Paratipos: 19, ZUPV/2021bis. 1 $0^{\Upsilon}+1$, ZUPV/2040, PNMA: Ayene, cabecera río. 19, ZUPV/2013, PNMA: Monte Alén, vertiente NW.

Etimología: Del latín spina, por alusión a la notable espinulación dorsal, que recuerda a las especies del género Nemastomella (Opiliones: Nemastomatidae)

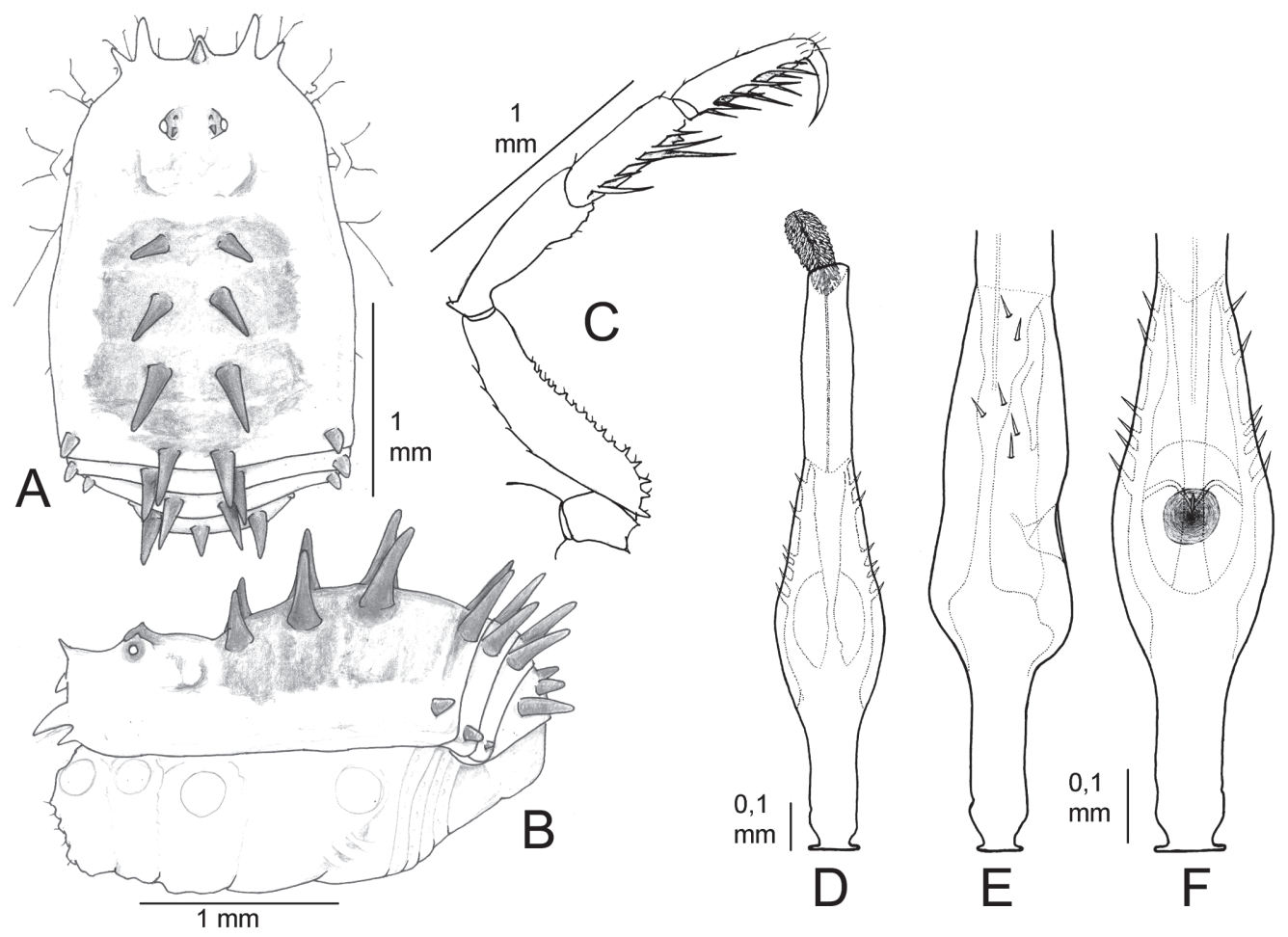

Fig. 20. Niefanga spinosa gen. \& sp. nov. Holotipo ${ }^{\top}$. A, dorsal; B, lateral; C, pedipalpo izquierdo (mesal); D, pene (ventral); E-F, tronco del pene (lateral y dorsal).

Fig. 20. Niefanga spinosa gen nov., sp. nov. Holotype $\mathrm{O}^{\top}$. A, dorsal; B, lateral; C, left palp (mesal); D, penis (ventral); E-F, penis trunk (lateral and dorsal). 
Descripción: Coloración (Fig. 10A). Amarillo pálido, salvo por un área reticulada en oscuro tras el tubérculo ocular y una mancha cuadrangular ocupando las áreas I-IV; espinas dorsales muy oscuras. Coxas y trocánteres de color amarillo pálido.

Cara dorsal (Fig. 20A-B). Tubérculo ocular pequeño, ovalado, centrado en el carapacho, con la zona central cóncava, y con un par de gránulos junto a cada ojo. Cuerno frontal grande. Longitud relativa de los procesos frontales, 36263. Áreas I-III con sendos pares de espinas muy largas y robustas, progresivamente mayores hacia la parte posterior; área IV desarmada. Área V y terguitos libres I-II con sendos pares de largas espinas centrales y un par de nítidas espinas marginales de mucho menor tamaño. Terguito libre III con tres espinas, la central de menor tamaño. Coxas I-II con sendos tubérculos dorsales, y tubérculos posteriores, el de la coxa II fusionado con un tubérculo de la coxa III formando un puente dorsal.

Cara ventral. Coxa I con tres filas de tubérculos, la anterior muy corta, formada por tres tubérculos, la central formada por 7-8 tubérculos de tamaño irregular; resto de coxas granulosas, con filas marginales de tubérculos. Espiráculos cubiertos por cuatro tubérculos digitiformes curvados contra la coxa IV. Coxas claramente separadas por un esternón. Esternitos provistos de hileras de gránulos. Opérculo anal de color pardo.

Pedipalpos (Fig. 20C). Trocánter con dos espinas ventrales, una en la zona central y otra en la apical; fémur ventralmente dentado en $2 / 3$ de su longitud, con un pequeño diente medioapical; patela con un diente dorsal en la curvatura; tibia ventromesalmente con cinco espinas (la $1^{\mathrm{a}}$ y la $4^{\mathrm{a}}$ más largas), ventrolateralmente con dos espinas apicales, la $1^{\mathrm{a}}$ más larga; tarso con cuatro espinas a cada lado. Pedipalpos ocre-amarillentos, con manchitas oscuras en la base de las espinas largas de tibia y tarso. Quelíceros. Artejo proximal con joroba granulosa.

Patas. Largas y finas, de color pardo. Fórmula tarsal: 5, 11-12 (3), 6, 7.
Pene (Fig. 20D). Fusiforme. Longitud, $1.3 \mathrm{~mm}$. Tronco del pene corto y cilíndrico, continuando sin discontinuidad con el engrosamiento vítreo distal. Cabeza penial fusiforme, con el glande en el extremo apical. Cara ventral desprovista de sedas. Cara lateral provista de seis sedas desalineadas, cuatro en la zona media y dos más separadas en la zona apical. Cara dorsal sin sedas. Colectores de la secreción penial desembocando en el interior de una fisura abierta en la pared superior de una excavación dorsal en forma de embudo. Glande tubular y cilíndrico, más largo que el tronco penial, con una escotadura en el borde dorsal del orificio distal, por donde asoma un cilindro espinoso ("Stacheltrichter") con aspecto plumoso.

Hembra (Fig. 10B-D). Similar al macho pero de mayor tamaño y con el área $\mathrm{V}$ del escudo con una larga espina central flanqueada por un par de pequeñas espinas y un par de espinas marginales; el terguito libre I puede presentar una única espina central en vez del par de espinas característico; coxas III muy separadas por un esternón triangular muy encajado que deja una escotadura semicircular hacia el orificio genital; esta escotadura nunca queda totalmente cerrada por un opérculo genital de forma trapezoidal, con su borde anterior provisto de un dentículo dirigido hacia la escotadura de la placa esternal.

Variabilidad. Se han observado diferencias en la armadura de los terguitos libres I y II en hembras.

\section{English diagnosis of new taxon}

Montalenia gen. nov. (Type species, Montalenia forficula sp. nov.)

Member of the subfamily Polycoryphinae with a frontal denticle and ocularium with a pair of long spines. Areas I-III with a paramedian pair of spines on each, areas IV-V unarmed, free tergites I-II with a small median spine and III with three long spines. Spiracles concealed by 2-3 digitiform processes. Coxae II-III separated by a reddish broad sternum. 
Tarsal formula: 5, 10-11 (3), 6, 7. Penis short and robust, with the glassy part dorsoventrally flattened, two short secretion collector tubes leading independently into dorsal surface; glans penis stands out between two small lobes. Female with very elongated abdomen and free tergite III with a hypertrophied trident.

\section{Género Montalenia nov.}

Especie típica: Montalenia forficula sp. nov.

Etimología: Del nombre de la localidad típica, Monte Alén, situada en el Parque Nacional del mismo nombre. Género gramatical, femenino.

Diagnosis: Región frontal del carapacho con un diente medial. Tubérculo ocular con un par de largas espinas. Áreas I-III con pares de espinas; áreas IV-V desarmadas; terguitos libres I-II con una pequeña espina media; terguito libre III con tres largas espinas. Coxas II y III separadas medialmente por un ancho esternón. Espiráculos cubiertos por 2-3 procesos quitinosos. Fórmula tarsal: 5, 10-11 (3), 6,7 . Pene corto y robusto con la parte vítrea dorsoventralmente aplanada, colectores de las glándulas peniales tubulares, simples y paralelos, glande curvado. Hembras con cuerpo dos veces más largo que en los machos, y terguito libre III con un tridente hipertrofiado.

Comentarios: Los géneros Montalenia, Ayenea y Niefanga forman un grupo dentro de la subfamilia junto con Binderella y quizás Bueana; todos ellos comparten una similar armadura dorsal, con las áreas I-IV del escudo con armadura 2, 2, 2, 0. Por otra parte, Starȩga (1992) ha propuesto la sinonimia de Tengelinia paradoxa, basada en una hembra procedente de Tengelin (Camerún), con Binderella bistriata, basada en dos machos procedentes de Binder (Norte de Camerún), ambas descritas por Roewer (1935). En los dibujos de Roewer se aprecia el exagerado dimorfismo sexual de esta especie: la corta espina del tercer terguito libre del macho se presenta en la hembra (de doble tamaño que el macho) como una gran estructura cónica, caudiforme, que alcanza los $3 \mathrm{~mm}$ de longitud (frente a los $6 \mathrm{~mm}$ del cuerpo) y llega a estar articulada. Es notable que Binderella y Montalenia (cuyo tridente puede alcanzar $2.5 \mathrm{~mm}$ en la hembra) compartan la misma tendencia al gigantismo de la armadura terminal, lo que reforzaría la relación entre dichos taxones. El pene de B. bistriata muestra notables similitudes que lo relacionan con este grupo: lóbulos apicales grandes y separados, ocupados por la glándula penial, colectores ampliamente separados y con gruesa raíz única, ensanchados terminalmente en una cavidad parcialmente ocupada por la masa glandular y por una espina curva que asoma por el orificio (datos no publicados).

\section{English diagnosis of new taxon}

Montalenia forficula sp. nov. (Holotype: MNCN, Madrid; type locality, Monte Alén National Park, Equatorial Guinea) Figs. 11, 21. Measurements in table 3.

Brown yellowish, with the blackish central zone of areas I-IV crossed by a clearer medial band; free tergites yellowish, dorsal spines dark; anal sclerites dark except the rear border of the last sternite. Body vaguely rectangular; carapace with small frontal horn, a low and small ocularium with a pair of long spines preceded by a pair of granules; relative length of frontal processes, 36263. Areas I-III with a pair of long central spines on each; areas IV-V unarmed excepting small protuberances on the posterior corners of the scutum; free tergite I unarmed, II with a median spine and III with three long spines. Coxae II and III connected by a cuticular bridge. Spiracles concealed by three long cuticular processes. Palp femur curved, with a mesoapical spine and ventrally serrated; patella unarmed; tibia with five ventromesal and two ventrolateral spines $\left(1^{\text {st }}\right.$ and $4^{\text {th }}$ longer); tarsus with five spines in each side. Basichelicerite with smooth bulla. Legs long and slender, brown but lighter tarsi III-IV; tarsal formula: 5, 10-11 (3), 6, 7. Penis claviform, 
with broad, dorsoventrally flattened stalk; penis head vitreous, ovate and dorsally swollen, with two widely separated apical lobes culminate in a conical protuberance with three setae; ventral side with a seta below each apical lobe, lateral and dorsal sides without setae; secretion collector tubes separated, parallel, narrow and leading level with penial surface; cylindrical glans with wide mouth. Female double larger than male, with lengthened post-scutum abdomen and spines of free tergite III modified into a long trident (with lateral spines curved towards median line); free tergites I-II with a small median spine; a broad yellow sternum; thick and granular genital operculum, with an anterior process acting as closing flap.

Montalenia forficula sp. nov.

(Figs. 11, 21)

Localidad típica: Parque Nacional de Monte Alén: Monte Alén, vertiente NO.

Holotipo: $\sigma^{\top} \quad(\mathrm{MNCN} / 20.02 / 17081$, ex-ZUPV/2012). Paratipos: $1 \sigma^{\top}+1{ }^{\circ}$, ZUPV/2012bis. $1 \sigma^{\top}+2$, Z, ZUPV/2024, Parque Nacional de Monte Alén: trayecto al Itinerario Pedagógico. $10^{\top}+1$,, $\mathrm{ZUPV} / 2011$, Parque

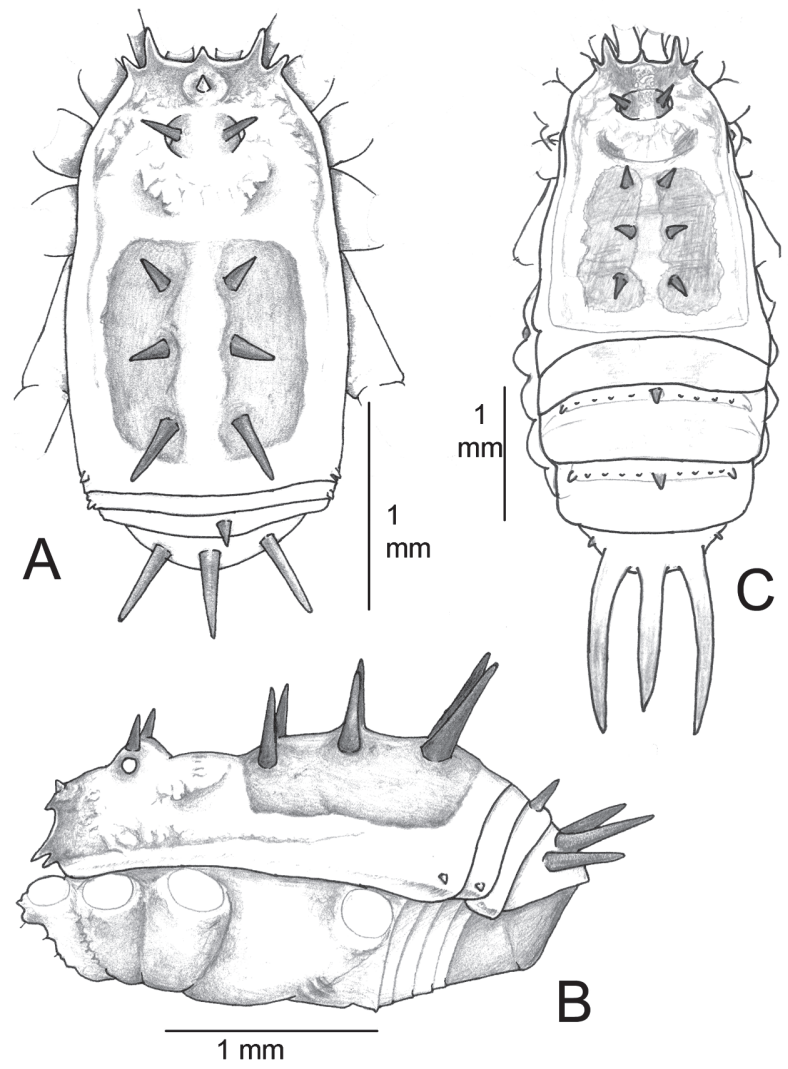

Fig. 21. Montalenia forficula gen. \& sp. nov. Holotipo $\sigma^{\text {T: }}$ (A-B, D-G) y paratipo $\mathrm{O}(\mathrm{ZUPV} / 2012: \mathrm{C})$. A, dorsal; B, lateral; $\mathrm{C}$, dorsal; D, pedipalpo derecho (lateral); E-G, pene (ventral, lateral y dorsal).
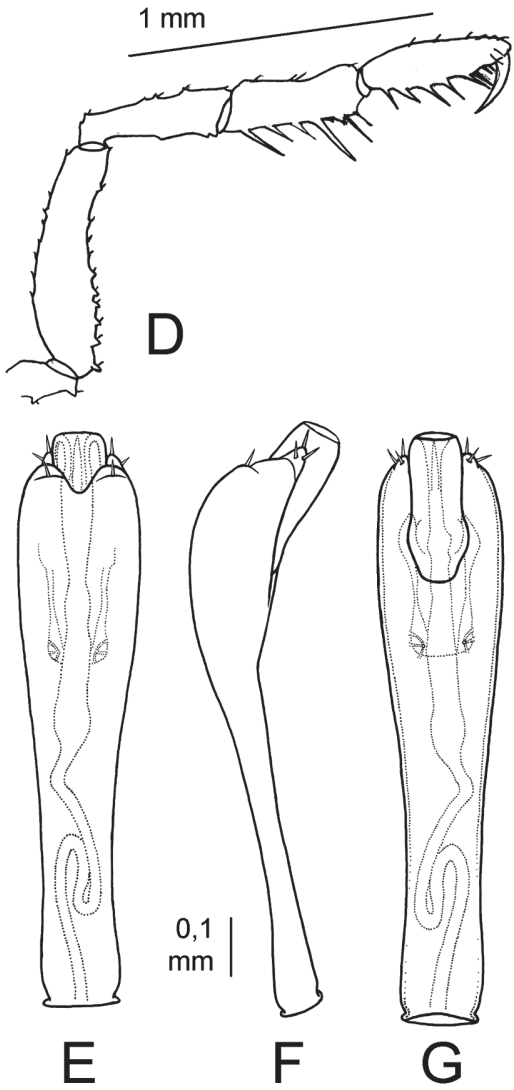

G

Fig. 21. Montalenia forficula gen. nov., sp. nov. Holotype $\sigma^{\top}$ (A-B, D-G) and paratype $\bigcirc$ (ZUPV/2012: C). A, dorsal; B, lateral; C, dorsal; D, rigth palp (lateral); E-G, penis (ventral, lateral and dorsal). 
Nacional de Monte Alén: Monte Alén. 10 ZUPV/2041, Parque Nacional de Monte Alén: camino del Mirador.

Etimología: Del vago parecido del alargado cuerpo de las hembras con el de algunos dermápteros, como Forficula auricularia, al estar armado con largas espinas caudales (aún teniendo una excedentaria central).

Descripción: Coloración (Fig. 11A). Cara dorsal color ocre amarillento, con la zona central de las áreas I-IV negra, de forma rectangular, excepto una franja media longitudinal más clara; terguitos libres amarillentos; espinas dorsales oscuras. Coxas y esternitos amarillos en la zona central, pasando a tener un color pardo en la zona lateral. Opérculo anal oscuro, salvo el borde posterior del último esternito.

Cara dorsal (Fig. 21A-B). Cuerpo de forma vagamente rectangular. Cuerno frontal prosómico de muy pequeño tamaño. Longitud relativa de los procesos frontales, 362631. Tubérculo ocular pequeño, más cercano al borde anterior, poco prominente, con un par de largas espinas junto a los ojos y un pequeño gránulo delante de cada espina. Superficie dorsal con aspecto granuloso. Áreas I-III con un par de largas espinas centrales; áreas IV-V inermes; área V con dos pequeñas protuberancias marginales; terguito libre I desarmado y terguito libre II con una espina media; terguito libre III con tres largas espinas. Coxas II-III unidas por un conspicuo puente cuticular.

Cara ventral. Coxa I con tres filas de tubérculos, la anterior corta formada por cuatro tubérculos, la central formada por 6-7 tubérculos de tamaño creciente, y la posterior con varios tubérculos de menor tamaño. Resto de coxas granulosas. Espiráculos protegidos por tres largos procesos cuticulares. Esternitos con una fila transversal de gránulos.

Pedipalpos (Fig. 20D). Trocánter con una pequeña espina ventral; fémur curvado, ventralmente dentado y con una pequeña espina mesoapical; patela de igual longitud que la tibia, sin espinas; tibia con cinco pequeñas espinas ventromesales (la $1^{\mathrm{a}}$ y la $4^{\mathrm{a}}$ algo más largas); ventrolateralmente con una espina próxima al extremo apical; tarso con cinco pequeñas espinas a cada lado. Color pardo con pigmentación más oscura en la base de las espinas largas de tibia y tarso. Quelíceros. Artejo proximal con joroba lisa, medio con algunos pelos dispersos. Color pardo. Patas. Finas y alargadas, de color pardo salvo tarsos de patas III y IV, que son más claros; metatarsos con pseudoarticulaciones. Fórmula tarsal: 5, 10-11 (3), 6, 7.

Pene (Fig. 21E-F). Claviforme. L= $1.05 \mathrm{~mm}$. Tronco del pene grueso y dorsoventralmente aplanado, con transición a la cabeza penial apreciable en vista lateral. Cabeza penial ovalada, vítrea, aplanada ventralmente y abombada dorsalmente, con dos lóbulos apicales separados por una ancha escotadura. Cara ventral con sendas sedas en la base de los lóbulos apicales, los cuales llevan una protuberancia cónica provista de tres sedas. Caras lateral y dorsal carentes de sedas. Colectores de la secreción penial estrechos, tubulares, paralelos y desembocando independientemente a ras. Glande troncocónico, con amplia abertura apical.

Hembra (Fig. 11B-D, 21C). Cuerpo muy alargado, prácticamente el doble de grande que el macho debido a la gran dilatación longitudinal de la parte post-escutal del abdomen, y con las espinas del terguito libre III mucho más largas y curvadas hacia dentro, formando un tridente; terguitos libres más oscuros, los terguitos I-II con una pequeña espina media; membranas articulares hinchadas. Patas, especialmente la III y la IV, más robustas. Coxas II y III netamente separadas por un esterno de color amarillo, ligeramente hundido entre las coxas III; opérculo genital de forma vagamente triangular, muy grueso, fuertemente granuloso, y provisto de una prolongación anterior a modo de solapa de cierre.

Variabilidad: La presencia de la espina en el terguito libre II no es un carácter constante en los machos. 


\section{DISCUSIÓN}

Una breve síntesis de los resultados, 10 especies de asámidos de las que ocho son nuevas, permite situar la cuestión: los opiliones afrotropicales se conocen tan fragmentariamente que cualquier colección proporcionará nuevas especies, quizás un tercio si la zona está algo estudiada o casi todas si se trata de una región no investigada, como ha ocurrido con Río Muni. Aún con esta contribución, la fauna opilionológica de la Región Continental de Guinea Ecuatorial continúa muy deficientemente conocida ya que los datos se refieren sólo a una pequeña parte del territorio.

La presente aportación está basada en los muestreos realizados en tres regiones relativamente pequeñas, el distrito de Cogo, el P.N. Monte Alén y la isla de Corisco, que no constituyen ni el 20\% de la superficie de la Región Continental de Guinea Ecuatorial. No hay duda que la diversidad de los opiliones de esta región debe ser mucho mayor que la conocida actualmente, producto de una única campaña de muestreo. De 11 localidades muestreadas, sólo en 9 se encontraron asámidos. Además, las diferentes localidades de procedencia del material no han sido muestreadas con la misma intensidad, lo que se traduce en el rendimiento del número de especies; así, las muestras procedentes del P.N. Monte Alén (unas 10 horas de muestreo) han proporcionado un total de 7 especies de asámidos, mientras que las del Río Motora (10 horas) y Río Congüe (5 horas) han proporcionado cinco y tres especies respectivamente; en cambio, las otras localidades han sido muestreadas menos intensivamente, lo que se traduce en un menor número de especies. Otro factor que podría contribuir a explicar las notables diferencias en el número de especies de Assamiidae es el hábitat; las localidades de "bosque primario" pueden dividirse en dos grupos, las de bosque virgen (nunca explotado, caso del P.N. Monte Alén, donde se han encontrado 7 especies) y las de bosque explotado (mediante entresaca durante la época colonial, hasta 1965), como son Río Congüe y Río Motora, que contribuyen con cinco y tres especies. Por el contrario, el resto de las localidades sólo han proporcionado una única especie.

La composición taxonómica también parece afectada por el hábitat: las tres especies de Polycoryphinae están representadas en el P.N. Monte Alén, pero ninguna de ellas ha sido encontrada en las localidades más cercanas a la costa o las de bosque secundario, con una fauna empobrecida dominada por los Selencinae. Los Erecinae e Hypoxestinae, que tampoco han sido encontrados en las localidades más alteradas, muestran el mismo patrón.

\section{RESUMEN}

Los Opiliones de Guinea Ecuatorial y su Región Continental (antiguamente conocida como Río Muni) no habían sido previamente estudiados. El material recogido en 1996 ha proporcionado 22 especies, de las que diez pertenecen a la familia Assamiidae y son objeto de este trabajo: Chilon robustus gen. nov., sp. nov. y Mbinia xenophora gen. nov., sp. nov. (Erecinae), Podauchenius longipes sp. nov. y Rhabdopygus funilignorum sp. nov. (Hypoxestinae), Ayenea trimaculata gen. nov., sp. nov., Montalenia forficula gen. nov., sp. nov. y Niefanga spinosa gen. nov., sp. nov. (Polycoryphinae), Binderia longipes sp. nov., Seuthes inermis sp. nov. y Seuthessus coriscanus sp. nov. (Selencinae). Se considera a Ayenea, Montalenia y Niefanga como un nuevo grupo supragenérico basado en la presencia de un par de orificios en el lado dorsal del pene y un grueso opérculo genital con mecanismo de apertura. Se añaden claves para la identificación de especies de los taxones tratados, así como fotografías a color de ambos sexos (excepto la hembra de $B$. longipes). En el Parque Nacional de Monte Alén se han encontrado ocho especies; solamente faltan de allí dos selencinos, aparentemente costeros.

Palabras clave: Opiliones, Assamiidae, Golfo de Guinea, Guinea Ecuatorial, Río Muni, Parque Nacional de Monte Alén.

\section{AGRADECIMIENTOS}

A Patxi Heras, compañero de expedición por toda su colaboración. A Mario Sarsa, director del Hospital de Cogo, Javier Arzallus, logista de la Asociación Africanista Manuel Iradier en Cogo, y Jesús, encargado de la maderera $\mathrm{ABM}$ que posibilitaron la logística de los muestreos en la cuenca del Río Muni. A Luis Arranz, por entonces director, y Simón, guía, 
que facilitaron y ayudaron en los muestreos en el Parque Nacional de Monte Alén. A los tres revisores del manuscrito, cuyos comentarios han permitido mejorar notablemente la calidad del manuscrito. El muestreo fue financiado por el proyecto UPV 154.310-EA 112/95 de la Universidad del País Vasco.

\section{REFERENCIAS}

Bauer, C. \& Prieto, C.E. 2009. Three new Assamiidae (Arachnida: Opiliones) from Cameroon, with a redescription of Chilon robustus and comments on related species. Zootaxa 2059: 1-22.

Bofill, A. \& J.B. Aguilar-Amat. 1924. Contribución al estudio de la fauna malacológica de las posesiones españolas del Golfo de Guinea. Trab. Museo Cienc. Nat. Barc. 10: 3-17.

Goodnight, C.J. \& M.L. Goodnight. 1944. New phalangids from the Old World. Amer. Mus. Nov. 1255: 1-6.

Giribet, G. \& C.E. Prieto. 2003. A new Afrotropical Ogovea (Opiliones, Cyphophthalmi) from Cameroon, with a discussion on the taxonomic characters in the family Ogoveidae. Zootaxa 329: 1-18.

Hansen, H.J. 1921. The Pedipalpi, Ricinulei, and Opiliones (exc. Op. Laniatores) collected by Mr. Leonardo Fea in tropical West Africa and adjacent islands, p. 5-55 +4 pl. In H.J. Hansen (ed.), Studies on Arthropoda 1. Glydendalske Boghandel, Copenhagen, Dinamarca.

Hidalgo, J.G. 1910. Moluscos de la Guinea Española. Mem. Soc. esp. Hist. nat. 1: 507-524.

Iradier, M. 1887. Producciones. África: viajes y trabajos de la asociación Euskara La Exploradora, Vol. 2: $157-173$

Kauri, H. 1985. Opiliones from Central Africa. Ann. Zool. Wetensch., Musée Royal de 1'Afrique Centrale (Tervuren) 245: 1-168.

Kury, A.B. 2004. A new genus of Triaenonychidae from South Africa (Opiliones, Laniatores). Rev. Ibér. Aracnol. 9: 205-210.

Kury, A.B. 2006. A new species of Graemontia Lawrence 1931, from the Western Cape, South Africa, with notes on the relationships of the genus (Opiliones: Laniatores: Triaenonychidae). Afr. Zool. 41: 45-50.
Kury, A.B. 2007. Assamiidae Sørensen 1884, p. 173-176. In R. Pinto-da-Rocha, G. Machado \& G. Giribet (eds.). Harvestmen: The biology of Opiliones. Harvard University, Cambridge, Massachusetts, EEUU.

Lawrence, R.F. 1949. A collection of Opiliones and Scorpiones from North-East Angola made by Dr. A. de Barros Machado in 1948. Publ. cult. Comp. Diam. Angola 6: 1-20.

Lawrence, R.F. 1951. A further collection of Opiliones from Angola made by Dr A. de Barros Machado in 1948-1949. Publ. cult. Comp. Diam. Angola 13: 29-44.

Lawrence, R.F. 1957. A third collection of Opiliones from Angola. Publ. cult. Comp. Diam. Angola 34: 51-66.

Lawrence, R.F. 1965. A small collection of Opiliones from the Ivory Coast of West Africa. Bull. Mus. Nat. Hist. nat. 36: 797-811.

Martens, J. 1986. Die grossgliederung der Opiliones und die evolution der ordnung (Arachnida). Actas X Congr. Intern. Aracnol. I: 289-310.

Mello-Leitão, C.F. 1949. Famílias, subfamílias, espécies e gêneros novos de opiliões e notas de sinonímia. Bol. Mus. nac. Rio Janeiro 94: 1-33.

Ossorio, A. 1886. Fernando Póo y el Golfo de Guinea: Apuntes de un Viaje. An. Hist. Nat. XI: 289-347.

Pinto-da-Rocha, R., 2007. Key to the families of Laniatores, p. 168-171. In Pinto-da-Rocha, R., G. Machado \& G. Giribet (eds.). Harvestmen: The biology of Opiliones. Harvard University, Cambridge, Massachusetts, EEUU.

Prieto, C.E. 1999. 'Nuevos' Opiliones (Arachnida) de la Isla de Bioko, Guinea Ecuatorial. Res. Conf. Com. XVII Jorn. Asoc. esp. Ent. 71-72.

Roewer, C.F. 1923. Die Weberknechte der Erde. Systematische Bearbeitung der bisher bekannten Opiliones. Jena: Gustav Fischer. vi +1116 pp.

Roewer, C.F. 1927. Cyphophthalmi, Phalangodidae, Assamidae. Weitere Weberknechte I. Abh. Herausg. Naturwiss. Ver. Bremen 26: 261-402 + 1 pl.

Roewer, C.F. 1935. Alte und neue Assamiidae. Weitere Weberknechte VIII. Veröff. Deutsch. Kol. Übers. Mus. Bremen 1: 1-168 + pl. 1-9. 
Roewer, C.F. 1940. Neue Assamidae und Trogulidae. Weitere Weberknechte X. Veröff. Deutsch. Kol. Übers. Mus. Bremen 3: 1-31+ pl. 1-2.

Roewer, C.F. 1942. Opiliones, Pedipalpi und Araneae von Fernando Poo. Veröff. Deutsch. Kol. Übers. Mus. Bremen 3: 244-258 + pl. 19

Roewer, C.F. 1949. Ueber Phalangodiden I. (Subfam. Phalangodinae, Tricommatinae, Samoinae.) Weitere Weberknechte XIII. Senckenbergiana 30: 11-61 + $14 \mathrm{pl}$.

Roewer, C.F. 1950. Opiliones und Solifuga aus Belgisch Congo. Rev. Zool. Bot. Afr. 44: 30-55.

Roewer, C.F. 1951. Einige in Höhlen und Termitenbauten gefundene Assamiidae (Opiliones) aus dem Belgischen Congo-Gebiet. Rev. Zool. Bot. Afr. 44: 321327.

Roewer, C.F. 1952. Opilioniden und Solifugen aus OstAfrika. Veröff. Überseemus. Bremen (A), 2: 87-90.

Roewer, C.F. 1953. Opiliones aus Französisch-Westafrika, gesammelt durch Herrn Dr A.Villiers. Bull. Inst. fr. Afr. Noire 15: 610-630.
Roewer, C.F. 1961. Le Parc National du Niokolo-Koba (deuxieme fascicule). IV. Opilioniden und Araneaen. Mem. Inst. fr. Afr. Noire (A) 62: 33-81.

Shear, W.A. 1982. Opiliones, p. 104-110. In S. P. Parker (ed.). Synopsis and classification of living organisms. Vol. 2. McGraw-Hill, Nueva York, EEUU.

Simon, E. 1903. Arachnides de la Guinée Espagnole. Mem. Soc. esp. Hist. nat. 1: 65-124.

Sørensen, W. 1896. Opiliones Laniatores a cl. Dr. Yngve Sjoestedt in Kamerun (Africa Centrali) collectos. Entom. Tidskrift 17: 177-202.

Starȩga, W. 1984. Revision der Phalangiidae (Opiliones). III. Die afrikanischen Gattungen der Phalangiinae, nebst Katalog aller afrikanischen Arten der Familie. Ann. Zool. Warszawa 38: 1-79.

Starȩga, W. 1992. An annotated check-list of Afrotropical harvestmen, excluding the Phalangiidae (Opiliones). Ann. Natal Mus. 33: 271-336.

Suzuki, S. 1985. A synopsis of the Opiliones of Thailand (Arachnida) I. Cyphophthalmi and Laniatores. Steenstrupia 11: 53-59. 
